\title{
Multi-Power Joint Peak-Shaving Optimization for Power System Considering Coordinated Dispatching of Nuclear Power and Wind Power
}

\author{
Qi Liu ${ }^{1}{ }^{1}$, Jie Zhao ${ }^{1, *} \mathbb{D}$, Youguo Shao ${ }^{2}$, Libin Wen ${ }^{3}$, Jianxu $\mathrm{Wu}^{3}$, Dichen Liu ${ }^{1}$ and Yuhui Ma ${ }^{1}$ \\ 1 School of Electrical Engineering and Automation, Wuhan University, Wuhan 430072, China \\ 2 State Grid Jiangxi Economic Research Institute, Nanchang 330096, China \\ 3 Electric Power Research Institute of Guangxi Power Grid Co., Ltd., Nanning 530023, China \\ * Correspondence: jiez_whu@whu.edu.cn
}

Received: 3 August 2019; Accepted: 28 August 2019; Published: 3 September 2019

\begin{abstract}
The matching characteristics of wind power output and nuclear power peak shaving are studied and the influence of coordinated dispatching of wind power and nuclear power on peak shaving flexibility and cost of the power grid is analyzed. Taking the lowest total operation cost of the system as the objective and considering the operation constraints, peak shaving cost of nuclear power units and the abandoned wind cost, a multi-power dispatching model for power system is proposed. In addition, in order to accurately optimize the output of nuclear power, a method of subdividing the peak shaving depth of nuclear power to linearize the constraint of nuclear power peak shaving is proposed. The analysis of example shows that the multi-power dispatching model considering the coordinated operation of wind and nuclear power has a high operation economy and can significantly reduce the amount of wind abandonment. The daily load tracking mode can be used for the participation of nuclear power units in daily peak shaving and the feasibility and necessity of coordinated wind-nuclear dispatching are verified.
\end{abstract}

Keywords: nuclear power; wind power consumption; power system; peak shaving constraint; optimal dispatching

\section{Introduction}

In recent years, with the increasing tension of the world's energy supply and the increasingly severe climate and environmental problems, vigorous development and consumption of clean energy has become the consensus of the world's energy and power industries [1,2]. Peak-shaving is one of the challenging problems that modern power systems are facing. In this area, lots of research, particularly on demand-side management, is focusing on solving this challenge [3,4].

In France, Germany, the United States and other European and American countries, the modern nuclear power units are designed with daily load tracking capability and can participate in the peak shaving of the power system [5]. In China, the nuclear power units are currently operating with base load except in special periods such as typhoon transit [6]. Meanwhile, current nuclear power plants in China have the capacity of peak shaving and frequency modulation in design and some of them have experience in peak shaving $[7,8]$.

Large-scale, random, intermittent wind power and large-capacity nuclear power plants are connected to the power grid, which puts higher requirements on the climbing rate of units such as thermal power $[9,10]$. With the continuous increase of peak-valley difference of load in coastal areas and the construction and development of wind and nuclear power units, the pressure of peak shaving in coastal areas will be seriously aggravated and the demand for wind and nuclear power to participate in daily peak shaving is becoming stronger [11-13]. 
Due to the negative peak shaving characteristics of wind power, it will force the conventional units to start and stop frequently, which is not in line with the principle of economic grid dispatching and leads to severe wind abandonment [14-16]. Therefore, for the coastal power systems with wind and nuclear power, it is of great significance to study the participation of nuclear power in peak shaving and coordinated dispatching with wind power for the economic operation of the power grid and the promotion of wind power consumption.

Nuclear power units generally do not participate in the peak shaving of the power system because of their safety and wind power due to its uncertainty will have a certain impact on peak shaving. So at present, the research at home and abroad seldom considers the combined peak shaving strategy of wind power and nuclear power but at the technical level, the contemporary nuclear power unit has a strong daily load tracking capability [17-20]. When nuclear power units take typical daily load tracking operation mode to participate in power grid peak shaving, it has a positive effect on alleviating the peak shaving pressure of the power grid [21-23]. However, the existing research has not considered the establishment of a nuclear power peak shaving scheduling model and coordinated scheduling with wind power.

Based on the peak shaving experience of French nuclear power units, from the aspects of the power regulation rate and peak shaving depth, nuclear power peak shaving has a certain flexibility [24-26]. On the issue of the joint operation strategy of nuclear power and other power sources, References $[27,28]$ proposed that nuclear power peak shaving can be used to absorb the excess wind power. The dispatching model with nuclear power participating in peak shaving can be established based on the cost and safety constraints of nuclear power peak shaving [29-31]. On this basis, an optimal dispatching model for the combined operation of nuclear power and other conventional energy sources can be constructed [32-34]. For the optimization method of nuclear power peak shaving, the fixed nuclear power peak shaving mode or the three-grade fixed peak shaving depth mode can be used [35-38] but these methods all set a fixed peak-shaving mode for nuclear power, so they cannot achieve precise optimization of peak shaving operation for nuclear power. At the same time, the coordinated dispatching between nuclear power, wind power and conventional power sources has not been taken into account.

In order to alleviate the peak shaving pressure of the power grid, reduce the frequent start-up and shutdown of conventional units and promote the absorption of wind power, this paper studies the multi-power joint optimal dispatching strategy, considering the participation of wind power and nuclear power. For the nuclear power peak-shaving optimization method and the wind-nuclear coordinated dispatching problem, the coastal power system including onshore wind power, offshore wind power and nuclear power is taken as the research object. Firstly, based on the characteristics of wind power output and nuclear power peak shaving, the matching characteristics between wind power and nuclear power peak shaving is analyzed. Then this paper takes economic dispatching as the principle, takes into account abandoned wind cost and peak shaving cost of nuclear power and proposes a wind-nuclear coordinated dispatch optimization model with multiple power sources. At the same time, a method of subdividing the peak shaving depth of nuclear power is proposed to linearize the constraint of nuclear power peak shaving. Finally, an example is given to analyze the economy of wind-nuclear coordinated dispatching and the impact of daily peak shaving mode on optimization results, which verifies the validity of the model and the method proposed.

\section{Peak Shaving Matching Characteristics of Wind Power and Nuclear Power}

\subsection{Characteristics of Wind Power Output}

According to the influence of wind power daily output on peak-valley difference of system load, the peak-shaving effect caused by wind power can be divided into positive peak-shaving effect and negative peak-shaving effect. The variation of daily output of wind power is shown in Figure 1. 


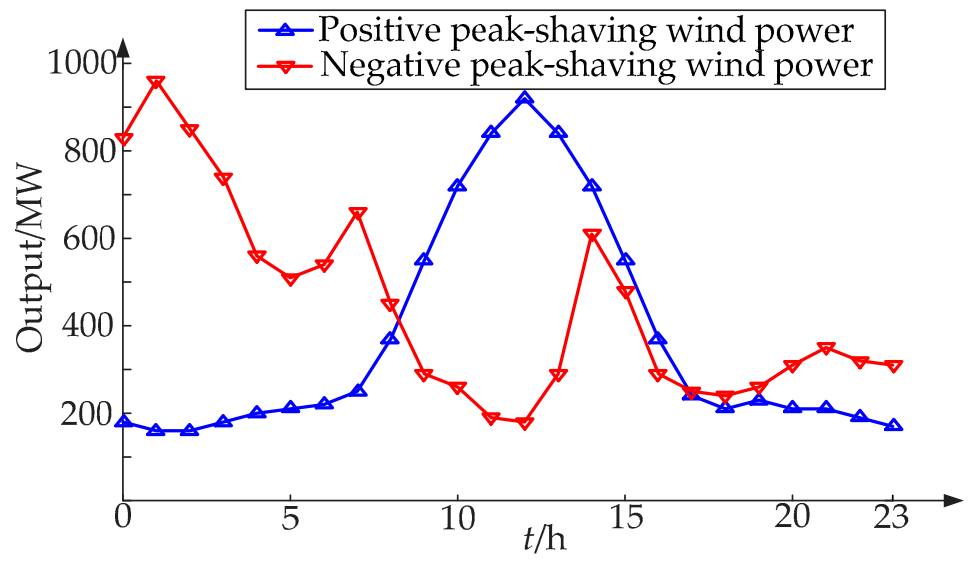

Figure 1. Daily output of wind power.

When the wind power output presents the characteristics of positive peak shaving, it can relieve the peak shaving pressure of the system. If it presents the characteristics of negative peak shaving, it requires the system to have more peak shaving capacity and increase the peak shaving pressure.

\subsection{Peak Shaving Characteristics of Nuclear Power}

Modern nuclear power units are designed with daily peak shaving capability. Within safety constraints, fast regulation of nuclear power can be achieved by adjusting the displacement of the control rod. Taking the current CPR1000 of nuclear power unit in China as an example, it has the ability of daily load tracking in the first $80 \%$ cycle life. It can participate in peak shaving according to the "12-3-6-3" mode, that is, full output of $12 \mathrm{~h}$ during peak load period, low power operation of $6 \mathrm{~h}$ during low load period and linear power up/down of $3 \mathrm{~h}$, as shown in Figure 2.

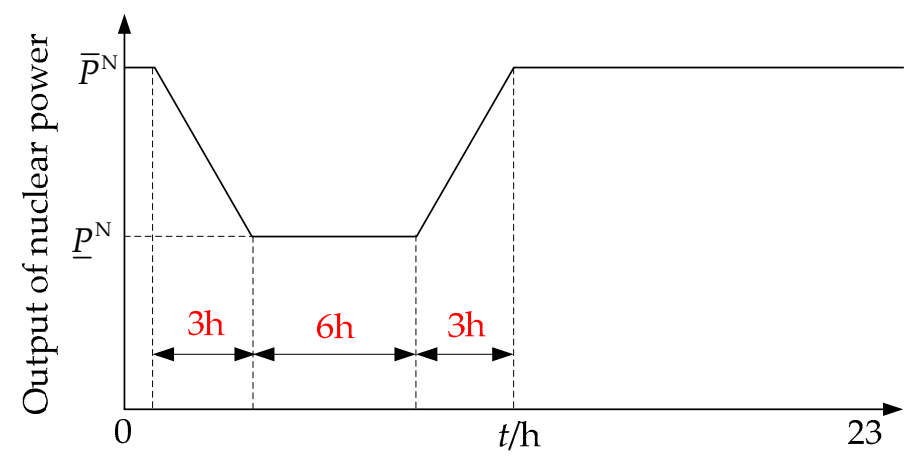

Figure 2. Daily peak shaving output of nuclear power.

It can be seen that, unlike conventional units, daily peak shaving of nuclear power has the characteristics of linear power rise and fall, constant output in low power period and long time in constant power period. In addition, nuclear power units need to meet the daily peak shaving limit, such as 5 times per week and 200 times per year. Therefore, from the safety point of view, it is necessary to avoid the frequent participation of a single nuclear power unit in daily peak shaving.

\subsection{Matching Characteristics of Wind Power Output and Nuclear Power Peak-Shaving}

Based on the above analysis of wind power output characteristics and peak shaving characteristics of nuclear power, it can be found that there are matching characteristics between the two, mainly reflected in two aspects:

(a) The negative peak shaving characteristics of wind power daily output can be matched with that of nuclear power daily peak shaving. When the wind power is in negative peak-shaving, it will 
cause the conventional units to operate or even shut down in low load period with near minimum technology output. The daily load tracking capability of nuclear power can provide peak-shaving capacity during low load period, thus alleviating the downward peak-shaving pressure caused by negative peak-shaving wind power, as shown in Figure 3.

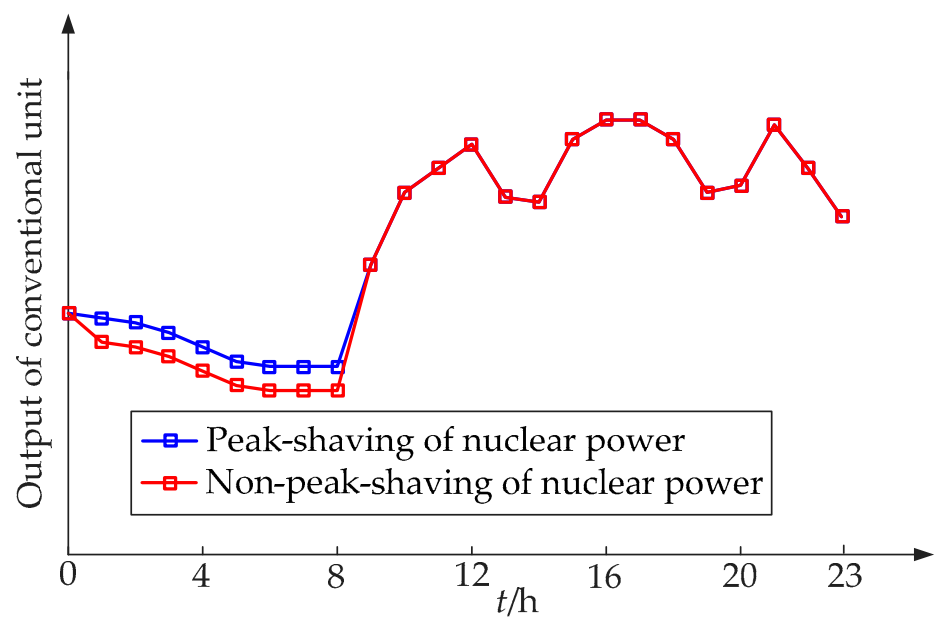

Figure 3. Power output of conventional units.

(b) The frequency of strong negative peak-shaving wind power can match the daily peak-shaving frequency of nuclear power. Due to operational safety constraints, nuclear power unit cannot be adjusted at will. Therefore, only when wind power has obvious negative peak shaving characteristics, nuclear power will be required to participate in daily peak shaving. Affected by wind speed variation and usability of wind turbine, the daily output of wind power may exhibit positive peak shaving, weak negative peak shaving and strong negative peak shaving characteristics. Therefore, nuclear power does not need to participate in daily peak shaving continuously and its daily peak shaving times can match the frequency of strong negative peak shaving wind power.

\section{Joint Dispatching Model of Multiple Power Sources}

\subsection{Treatment for Nuclear Power Units Participate in Daily Peak Shaving}

For several peak shaving nuclear power units $\mathrm{U}_{i}^{\mathrm{N}}\left(i=1,2, \ldots, n_{\mathrm{N}}\right)$, due to the limitation of daily peak shaving frequency in the week, year and operation period, the peak shaving units participate in daily peak shaving by turns in the actual operation. In order to ensure a longer period of daily peak shaving constraints and a balanced peak shaving electric-rejection rate among nuclear power units belonging to different interests, this paper compares all the nuclear power units to one peak shaving nuclear power unit $\mathrm{U}_{\mathrm{e}}^{\mathrm{N}}$ and use it to optimize the day-ahead dispatching.

If the day-ahead dispatching optimization results require nuclear power units to participate in peak shaving, on the basis of considering the daily peak shaving situation of each nuclear power unit in recent period, the dispatching operator will specify the designated nuclear power unit to participate in peak shaving every other day. The day-ahead dispatching plan of the designated peak shaving nuclear power unit is determined according to the day-ahead output optimization results of the equivalent nuclear power unit. If the day-ahead dispatching optimization result does not require nuclear power, so there is no need to designate nuclear power units to participate in peak shaving. For non-nuclear power units, regardless of peak shaving or not, the output arrangement is based on the day-ahead dispatching optimization results. 


\subsection{Objective Function}

In order to realize the economic dispatching of the power grid in the coastal area, the model considers the abandoned wind cost and peak shaving cost of nuclear power. The objective function is to minimize the total operation cost of multi-power-sources including coal-fired units, gas-steam combined cycle units, wind power units (including onshore and offshore), nuclear power units and pumped storage units:

$$
\mathrm{C}=\mathrm{C}_{\mathrm{T}}+\mathrm{C}_{\mathrm{CC}}+C_{\text {Wind }}+C_{\mathrm{Nuc}}+C_{\mathrm{PS}}
$$

(i) Operation cost of coal-fired units:

The operation cost of coal-fired units includes coal-burning cost and start-stop cost, which can be expressed as:

$$
C_{\mathrm{T}}=\sum_{t=1}^{24} \sum_{i=1}^{n_{\mathrm{T}}}\left[u_{i, t}^{\mathrm{T}} a_{i}^{\mathrm{T}}+b_{i}^{\mathrm{T}} P_{i, t}^{\mathrm{T}}+c_{i}^{\mathrm{T}}\left(P_{i, t}^{\mathrm{T}}\right)^{2}+S_{i, t}^{\mathrm{T}}\right]
$$

Start-stop cost of coal-fired units:

$$
S_{i, t}^{\mathrm{T}}=\alpha_{i, t^{\mathrm{T}}}^{\mathrm{T}} S_{i, \text { start }}^{\mathrm{T}}+\beta_{i, t_{i, \text { stop }}^{\mathrm{T}}}^{\mathrm{T}}
$$

(ii) Operation cost of gas-steam combined cycle units:

The operation cost of a gas-steam combined cycle unit includes (i) gas cost and (ii) mode conversion cost, which can be expressed as:

$$
C_{\mathrm{CC}}=\sum_{t=1}^{24} \sum_{i=1}^{n_{\mathrm{CC}}} \sum_{y \in M_{\mathrm{CC}}}[\underbrace{u_{i, t, y}^{\mathrm{CC}} a_{i, y}^{\mathrm{CC}}+b_{i, y}^{\mathrm{CC}}\left(u_{i, t, y}^{\mathrm{CC}} P_{i, y}^{\mathrm{CC}}+\Delta P_{i, t, y}^{\mathrm{CC}}\right)}_{i}+\underbrace{\left.\sum_{z \in M_{\mathrm{CC}}^{y}} s_{i, y z}^{\mathrm{CC}} v_{i, t, y z}^{\mathrm{CC}}\right]}_{i i}
$$

(iii) Cost of wind power abandonment:

The cost of wind power abandonment includes (i) the cost of onshore wind power abandonment and (ii) offshore wind power abandonment.

$$
C_{\text {Wind }}=\underbrace{p_{\mathrm{W}, \text { on }} \Delta E_{\mathrm{W}, \text { on }}}_{i}+\underbrace{p_{\mathrm{W}, \text { off }} \Delta E_{\mathrm{W}, \text { off }}}_{i i}
$$

Abandoned wind power can be calculated by the following formula:

$$
\left\{\begin{aligned}
\Delta E_{\mathrm{W}, \mathrm{on}} & =\sum_{t=1}^{24} \sum_{i=1}^{n_{\mathrm{W}, \mathrm{on}}}\left(P_{i, t}^{\mathrm{W}, \mathrm{on}, \text { Pre }}-P_{i, t}^{\mathrm{W}, \mathrm{on}}\right) \\
\Delta E_{\mathrm{W}, \mathrm{off}} & =\sum_{t=1}^{24} \sum_{i=1}^{n_{\mathrm{W}, \mathrm{off}}}\left(P_{i, t}^{\mathrm{W}, \mathrm{off}, \text { Pre }}-P_{i, t}^{\mathrm{W}, \mathrm{off}}\right)
\end{aligned}\right.
$$

(iv) Operation cost of nuclear power units:

When peak shaving cost is taken into account, the operation cost of nuclear power can be expressed as:

$$
C_{\mathrm{Nuc}}=\sum_{t=1}^{24}\left[a_{\mathrm{e}}^{\mathrm{N}}+b_{\mathrm{e}}^{\mathrm{N}} P_{\mathrm{e}, t}^{\mathrm{N}}+p_{N}\left(\bar{P}_{\mathrm{e}}^{\mathrm{N}}-P_{\mathrm{e}, t}^{\mathrm{N}}\right)\right]
$$


The equivalent nuclear power unit $\mathrm{U}_{\mathrm{e}}^{\mathrm{N}}$ is formed by the aggregation of several nuclear power units $\mathrm{U}_{i}^{\mathrm{N}}$. The cost coefficient of $\mathrm{U}_{\mathrm{e}}^{\mathrm{N}}$ and $\mathrm{U}_{i}^{\mathrm{N}}$ are the same and the operation cost constant and rated output of $\mathrm{U}_{\mathrm{e}}^{\mathrm{N}}$ are the cumulative sum of $\mathrm{U}_{i}^{\mathrm{N}}$ :

$$
\left\{\begin{array}{l}
a_{\mathrm{e}}^{\mathrm{N}}=\sum_{i=1}^{n_{\mathrm{N}}} a_{i}^{\mathrm{N}} \\
\bar{P}_{\mathrm{e}}^{\mathrm{N}}=\sum_{i=1}^{n_{\mathrm{N}}} \bar{P}_{i}^{\mathrm{N}}
\end{array}\right.
$$

The peak shaving cost factor of nuclear power combines (i) the additional fuel cost and (ii) safety cost caused by peak shaving, which can be expressed as:

$$
p_{\mathrm{N}}=\underbrace{p_{\mathrm{N}, \mathrm{f}}}_{i}+\underbrace{\sigma p_{\mathrm{N}, \mathrm{s}}}_{i i}
$$

(v) Operation cost of pumped storage units:

The operation cost of pumped storage unit only considers its start-up cost, which can be expressed as:

$$
C_{\mathrm{PS}}=\sum_{t=1}^{24} \sum_{i=1}^{n_{\mathrm{PS}}}\left(\alpha_{i, t}^{\mathrm{G}} s_{i, \text { start }}^{\mathrm{G}}+\alpha_{i, t}^{\mathrm{P}} \mathrm{S}_{i, \text { start }}^{\mathrm{P}}\right)
$$

\subsection{Constraint Condition}

(a) System constraints.

(i) Power balance constraint:

$$
\sum_{i=1}^{n_{\mathrm{T}}} P_{i, t}^{\mathrm{T}}+\sum_{i=1}^{n_{\mathrm{CC}}} P_{i, t}^{\mathrm{CC}}+\sum_{i=1}^{n_{\mathrm{W}, \text { on }}} P_{i, t}^{\mathrm{W}, \text { on }}+\sum_{i=1}^{n_{\mathrm{W}, \text { off }}} P_{i, t}^{\mathrm{W}, \text { off }}+P_{\mathrm{e}, t}^{\mathrm{N}}+\sum_{i=1}^{n_{\mathrm{PS}}} P_{i, t}^{\mathrm{PS}}=P_{t}^{\mathrm{L}}
$$

(ii) Reserve capacity constraints:

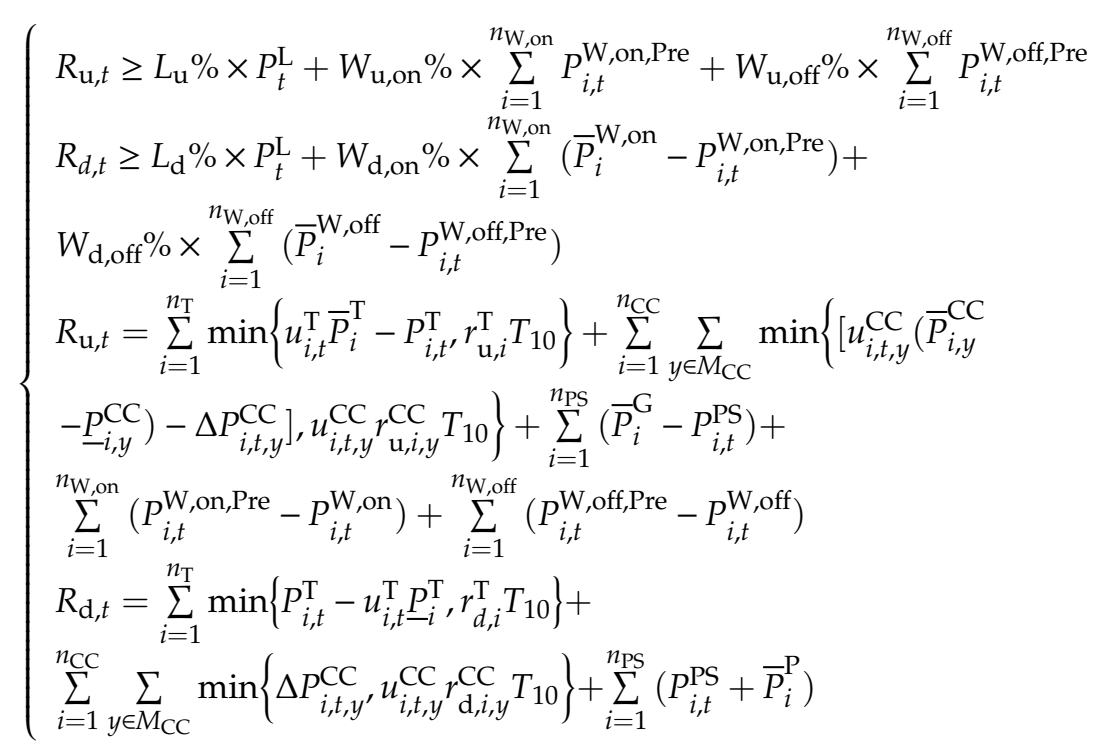

Among them, the first one is the positive rotation reserve constraint of the system and the second one is the negative rotation reserve constraint.

(b) Unit operation constraints: 
The constraints are given as follows:

$$
\begin{aligned}
& \left\{\begin{array}{l}
u_{i, t}^{T} P_{i}^{T} \leq P_{i, t}^{T} \leq u_{i, t}^{T} \bar{P}_{i}^{T} \\
-r_{d, i}^{T} \leq P_{i, t}^{T}-P_{i, t-1}^{T} \leq r_{u, i}^{T} \\
u_{i, x}^{T} \geq u_{i, t}^{T}-u_{i, t-1}^{T}, x \in\left[t, \min \left(t+\underline{T}_{-o n, i}^{T}-1,24\right)\right] \\
u_{i, x}^{T} \leq 1-\left(u_{i, t-1}^{T}-u_{i, t}^{T}\right), x \in\left[t, \min \left(t+\underline{T}_{\text {off }, i}^{T}-1,24\right)\right]
\end{array}\right. \\
& \left\{\begin{array}{l}
0 \leq \Delta P_{i, t, y}^{\mathrm{CC}} \leq u_{i, t, y}^{\mathrm{CC}}\left(\bar{P}_{i, y}^{\mathrm{CC}}-\underline{P}_{i, y}^{\mathrm{CC}}\right) \\
\Delta P_{i, t-1, y}^{\mathrm{CC}}-\Delta P_{i, t, y}^{\mathrm{CC}}-\sum_{z \in M_{\mathrm{C}}^{y}} \Delta P_{i, t, z}^{\mathrm{CC}} \leq u_{i, t-1, y}^{\mathrm{CC}} r_{\mathrm{d}, i, y}^{\mathrm{CC}} \\
-\sum_{z \in M_{\mathrm{CC}}^{y}} v_{i, t, y z}^{\mathrm{CC}}\left(r_{\mathrm{d}, i, y}^{\mathrm{CC}}+\underline{P}_{i, y}^{\mathrm{CC}}-\underline{P}_{i, z}^{\mathrm{CC}}-r_{\mathrm{d}, i, y z}^{\mathrm{CC}}\right) \\
\Delta P_{i, t, y}^{\mathrm{CC}}-\Delta P_{i, t-1, y}^{\mathrm{CC}}-\sum_{z \in M_{\mathrm{CC}}^{y}} \Delta P_{i, t-1, z}^{\mathrm{CC}} \leq u_{i, t, y}^{\mathrm{CC}} r_{\mathrm{u}, i, y}^{\mathrm{CC}} \\
-\sum_{z \in M_{\mathrm{CC}}^{y}} v_{i, t, z y}^{\mathrm{CC}}\left(r_{u, i, y}^{\mathrm{CC}}+\underline{P}_{i, y}^{\mathrm{CC}}-\underline{P}_{i, z}^{\mathrm{CC}}-r_{\mathrm{u}, i, z y}^{\mathrm{CC}}\right) \\
u_{i, x, y}^{\mathrm{CC}} \geq u_{i, t, y}^{\mathrm{CC}}-u_{i, t-1, y^{\prime}}^{\mathrm{CC}} x \in\left[t, \min \left(t+\underline{T}_{\mathrm{on}, i, y}^{\mathrm{CC}}-1,24\right)\right] \\
u_{i, x, y}^{\mathrm{CC}} \leq 1-u_{i, t-1, y}^{\mathrm{CC}}+u_{i, t, y^{\prime}}^{\mathrm{CC}} x \in\left[t, \min \left(t+\underline{T}_{\mathrm{off}, i, y}^{\mathrm{CC}}-1,24\right)\right]
\end{array}\right. \\
& \left\{\begin{array}{l}
0 \leq P_{i, t}^{\mathrm{W}, \text { on }} \leq P_{i, t}^{\mathrm{W}, \text { on,Pre }} \\
0 \leq P_{i, t}^{\mathrm{W}, \text { off }} \leq P_{i, t}^{\mathrm{W}, \text { off,Pre }}
\end{array}\right.
\end{aligned}
$$

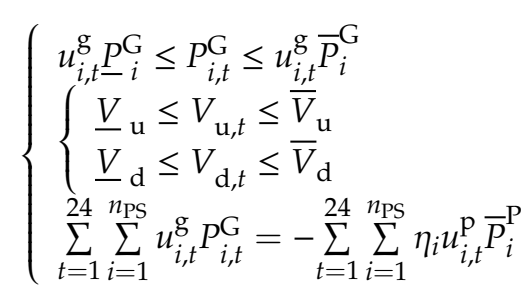

The output constraints, climbing speed constraints and minimum start-stop time constraints of coal-fired units are presented by (13). The output constraint, climbing rate constraint and minimum start-stop time constraint of combined cycle units is given by (14). Limits on wind power output are presented by (15). The power constraints, upper and lower storage capacity constraints and daily pumping capacity constraints of pumped storage units are considered by (16).

\section{Model Solving Method}

\subsection{Linearization of Peak Shaving Constraints in Nuclear Power Units}

Nuclear power peak shaving includes state constraints, output constraints and operation time constraints. Its output constraints are non-linear, which makes wind-nuclear coordinated dispatching a non-linear mixed 0-1 integer programming problem, which makes the solution difficult.

If the peak shaving depth and power state of each period are optimized simultaneously, it will lead to the non-linear expression of nuclear power output. In order to solve the model efficiently, it is necessary to determine one of the decision variables. Therefore, this paper presents a method of subdividing peak shaving depth to linearize the constraint of nuclear power peak shaving. Its main principle is to set enough fixed peak shaving depth to evenly distribute it in the range of nuclear power safety peak shaving depth, that is to say, the optimal variable of nuclear power peak shaving depth is discretized to a fixed value, thus realizing the linearized expression of nuclear power output. 
Assuming that the range of peak shaving depth for nuclear power safety is divided into $n_{\mathrm{d}}$ grades, the peak shaving depth of the $m$-th grade is as follows:

$$
P_{\mathrm{e}, \mathrm{d}, m}^{\mathrm{N}}=\frac{m}{n_{\mathrm{d}}}\left(\bar{P}_{\mathrm{e}}^{\mathrm{N}}-\underline{P}_{\mathrm{e}}^{\mathrm{N}}\right)
$$

Figure 4 shows the power stages and states of the nuclear power units under the peak shaving depth of the $m$-th grade. The output of nuclear power at the low-power stage is as follows:

$$
P_{l, m}^{\mathrm{N}}=\bar{P}_{\mathrm{e}}^{\mathrm{N}}-P_{\mathrm{e}, \mathrm{d}, m}^{\mathrm{N}}
$$

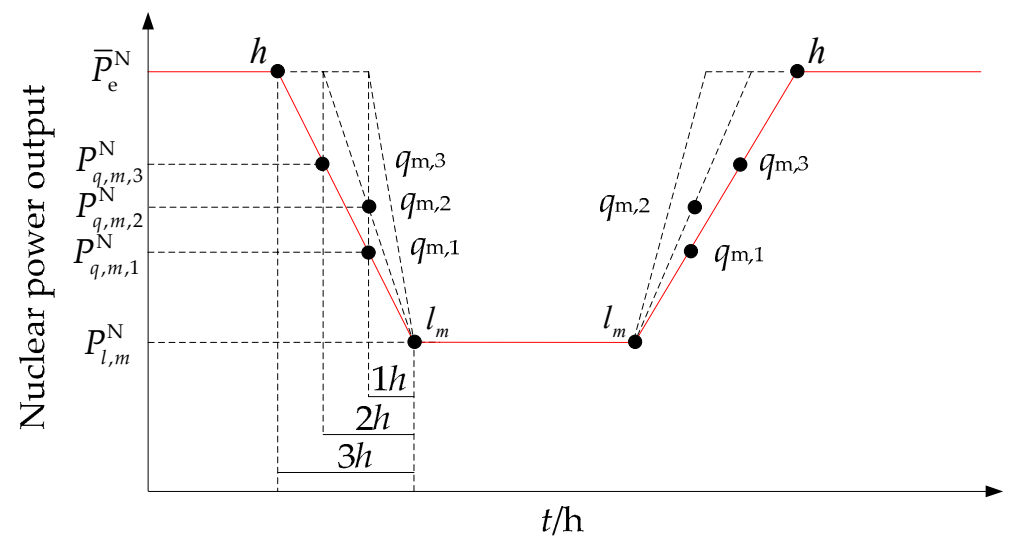

Figure 4. Output and state of nuclear power under the peak shaving depth of $m$.

Normally, the power-up/down time of nuclear power unit is $1 \sim 3 \mathrm{~h}$, so there are three power-up/down states for each peak shaving depth of nuclear power unit: $q_{\mathrm{m}, 1}, q_{\mathrm{m}, 2}, q_{\mathrm{m}, 3}$ and the corresponding power is:

$$
P_{q, m, j}^{\mathrm{N}}=P_{l, m}^{\mathrm{N}}+\frac{j+1}{6} P_{\mathrm{e}, \mathrm{d}, m}^{\mathrm{N}}
$$

where $j$ is the state label of power-up/down.

Then the nuclear power output can be expressed linearly as follows:

$$
P_{\mathrm{e}, t}^{\mathrm{N}}=h_{t} \bar{P}_{\mathrm{e}}^{\mathrm{N}}+\sum_{m=1}^{n_{\mathrm{d}}} l_{m, t} P_{l, m}^{\mathrm{N}}+\sum_{m=1}^{n_{\mathrm{d}}} \sum_{j=1}^{3} q_{m, j, t} P_{q, m, j}^{\mathrm{N}}
$$

Operating mark satisfies constraints:

$$
h_{t}+\sum_{m=1}^{n_{\mathrm{d}}} l_{m, t}+\sum_{m=1}^{n_{\mathrm{d}}} \sum_{j=1}^{3} q_{m, j, t}=1
$$


Similar to coal-fired units, the constraints of rated power and low power operation time of linearized nuclear power units are presented as follows:

$$
\left\{\begin{array}{l}
h_{m, x} \geq h_{m, t}-h_{m, t-1}, x \in\left[t, \min \left(t+\underline{T}_{h}^{\mathrm{N}}-1,24\right)\right] \\
l_{m, x} \geq l_{m, t}-l_{m, t-1}, x \in\left[t, \min \left(t+\underline{T}_{l}^{\mathrm{N}}-1,24\right)\right]
\end{array}\right.
$$

In the power-up/down stage, there are time-coupling constraints in operation mark. Coupling constraints of operation mark when the power up/down time is $2 \mathrm{~h}$ :

$$
\left\{\begin{array}{l}
h_{t+1} \geq q_{m, 2, t}+l_{m, t-1}-1 \\
l_{m, t+1} \geq q_{m, 2, t}+h_{t-1}-1
\end{array}\right.
$$

Coupling constraints of operation mark when the power up/down time is $3 \mathrm{~h}$ :

$$
\left\{\begin{array}{c}
h_{t+1} \geq q_{m, 3, t}+q_{m, 1, t-1}-1 \\
l_{m, t+1} \geq q_{m, 1, t}+q_{m, 3, t-1}-1 \\
q_{m, 1, t+1} \geq q_{m, 3, t}+h_{t-1}-1 \\
q_{m, 3, t+1} \geq q_{m, 1, t}+l_{m, t-1}-1
\end{array}\right.
$$

It should be noted that, compared with base-load operation, peak shaving of nuclear power will result in additional operation and maintenance costs (including additional costs for spent fuel reprocessing) and different peak shaving depths and xenon poision reactions will also affect the lower limit of low power operation time. Because of the additional operation and maintenance costs and the impact on the lower limit of low power operation time due to different peak shaving depths of nuclear power, there is still a lack of sufficient data analysis and quantification, so it is not considered for the time being.

\subsection{Model Solving Process}

Figure 5 is the flow chart of wind-nuclear coordinated dispatching model, which is mainly divided into two parts-model linearization, model solution and dispatching plan formulation. Among them, the role of model linearization is to standardize dispatching model to achieve the efficient solution of it based on commercial optimization software Cplex. Dispatching plan is to consider the limitation of peak shaving times per day, arrange the nuclear power unit in turn and realize the balance of peak shaving and nuclear discarding among the nuclear power units belonging to different interests. 


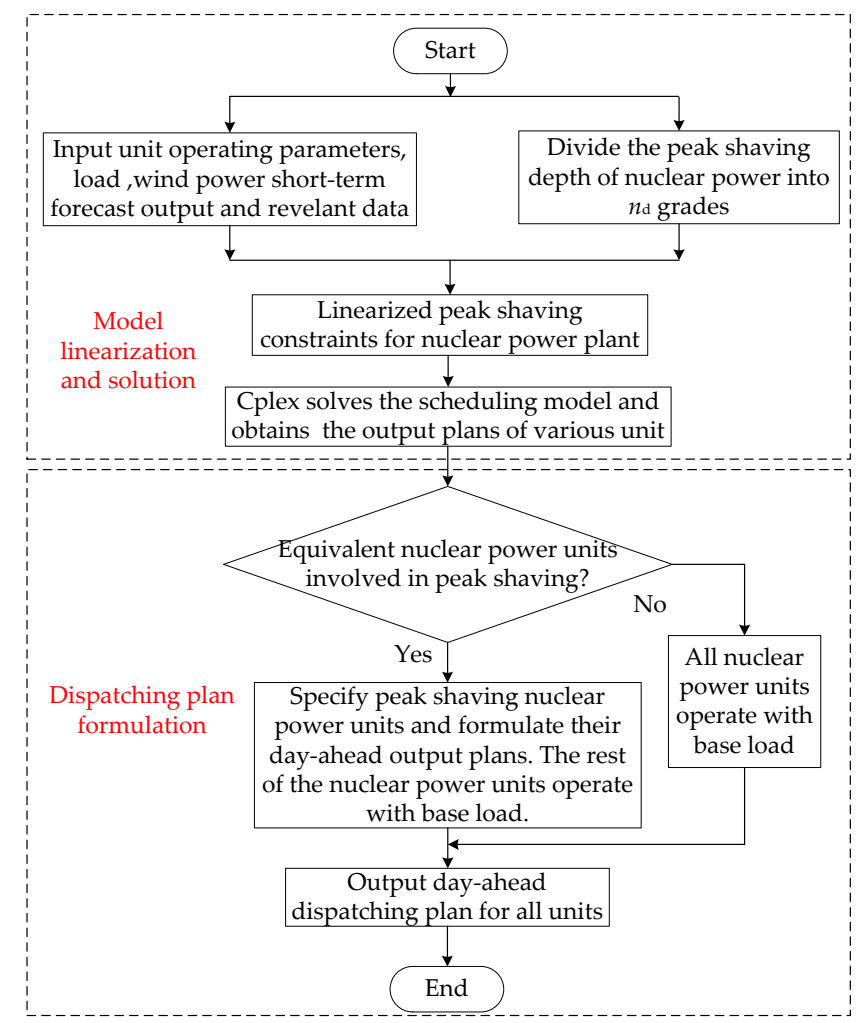

Figure 5. Solving flow of coordinated dispatching model of wind and nuclear power.

\section{Example Analysis}

The data in this section is based on the improvement of a regional power system [39-43], the basic situation of the power system is as follows-three nuclear power units including CNP600 in Qinshan nuclear power station and AP1000 in Sanmen nuclear power station; one onshore wind farm and one offshore wind farm with $1000 \mathrm{MW}$ installed in Zhoushan and Ningbo; two gas-steam combined cycle units in Wenzhou power station; three pumped storage units of Xianju pumped storage power station; 28 coal-fired units from six thermal power stations (Lanxi, Yueqing, Jiaxing, Xiaoshan, Yuhuan and Wuxijiang). The total installed capacity is $12,965 \mathrm{MW}$ and the relevant parameters are listed in Tables 1-4. 
Table 1. Parameters of coal-fired units.

\begin{tabular}{|c|c|c|c|c|c|c|c|c|c|}
\hline \multirow{2}{*}{$\begin{array}{c}\text { Unit } \\
\text { Capacity/MW }\end{array}$} & \multirow{2}{*}{$\begin{array}{c}\text { Number of } \\
\text { Units }\end{array}$} & \multicolumn{3}{|c|}{ Operation Cost Coefficient } & \multirow{2}{*}{$\begin{array}{c}\text { Start-Up } \\
\text { Cost } / \$\end{array}$} & \multirow{2}{*}{$\begin{array}{c}\text { Downtime } \\
\text { Cost } / \$\end{array}$} & \multirow{2}{*}{$\begin{array}{c}\text { Output Upper } \\
\text { (Lower) Limit/MW }\end{array}$} & \multirow{2}{*}{$\begin{array}{l}\text { Minimum Startup } \\
\text { (Downtime)/h }\end{array}$} & \multirow{2}{*}{$\begin{array}{c}\text { Climbing } \\
\text { Rate/(MW/h) }\end{array}$} \\
\hline & & $\mathrm{a} /(\$ / \mathrm{h})$ & $\mathrm{b} /(\$ /(M W \cdot h))$ & $c /\left(\$ /(M W \cdot h)^{2}\right)$ & & & & & \\
\hline 60 & 3 & 689.55 & 27.08 & 0.00431 & 8358.21 & 2089.55 & $60(27)$ & $4(3)$ & 18 \\
\hline 120 & 5 & 710.45 & 17.24 & 0.00220 & $16,716.42$ & 4179.10 & $120(54)$ & $4(3)$ & 36 \\
\hline 125 & 3 & 731.34 & 17.34 & 0.00209 & $17,412.99$ & 4353.28 & $125(56)$ & $4(3)$ & 38 \\
\hline 390 & 17 & 1044.78 & 16.91 & 0.00050 & $54,328.36$ & $13,582.09$ & 390 (176) & $6(4)$ & 117 \\
\hline
\end{tabular}

Table 2. Parameters of combined cycle units.

\begin{tabular}{|c|c|c|c|c|c|c|c|c|c|c|c|c|}
\hline \multirow{2}{*}{$\begin{array}{c}\text { Unit } \\
\text { Capacity/MW }\end{array}$} & \multirow{2}{*}{$\begin{array}{l}\text { Number } \\
\text { of Units }\end{array}$} & \multirow{2}{*}{ Mode } & \multicolumn{5}{|c|}{ Conversion Cost between Modes/\$ } & \multicolumn{2}{|c|}{ Operation Cost Coefficient } & \multirow{2}{*}{$\begin{array}{c}\text { Output Upper } \\
\text { (Lower) } \\
\text { Limit/MW } \\
\end{array}$} & \multirow{2}{*}{$\begin{array}{c}\text { Minimum } \\
\text { Startup Time } \\
\text { (Downtime)/h }\end{array}$} & \multirow{2}{*}{$\begin{array}{c}\text { Climbing } \\
\text { Rate/(MW/h }\end{array}$} \\
\hline & & & M0 & M1 & M2 & M3 & M4 & $a /(\$ / h)$ & $\mathbf{b} /(\$ /(M W \cdot h))$ & & & \\
\hline \multirow{5}{*}{180} & \multirow{5}{*}{1} & M0 & 0 & 433.43 & 1550.9 & 0 & 0 & 0 & 0 & $0(0)$ & $3(3)$ & 0 \\
\hline & & M1 & 516.42 & 0 & 1503.28 & 602.54 & 0 & 133.73 & 13.7 & $63(14)$ & $3(3)$ & 16.2 \\
\hline & & M2 & 1668.06 & 1334.33 & 0 & 0 & 960.9 & 265.27 & 13.7 & $126(29)$ & $3(3)$ & 32.4 \\
\hline & & M3 & 0 & 587.01 & 0 & 0 & 983.58 & 213.11 & 11.33 & $90(22)$ & $3(3)$ & 22.8 \\
\hline & & M4 & 0 & 0 & 1044.93 & 855.67 & 0 & 358.49 & 9.72 & $180(45)$ & $3(3)$ & 45 \\
\hline \multirow{5}{*}{300} & \multirow{5}{*}{1} & M0 & 0 & 722.39 & 2584.78 & 0 & 0 & 0 & 0 & $0(0)$ & $3(3)$ & 0 \\
\hline & & M1 & 860.75 & 0 & 2505.37 & 1004.18 & 0 & 222.63 & 13.7 & $105(24)$ & $3(3)$ & 27 \\
\hline & & M2 & 2780.15 & 2224.03 & 0 & 0 & 1601.49 & 442.12 & 13.7 & $210(48)$ & $3(3)$ & 54 \\
\hline & & M3 & 0 & 978.36 & 0 & 0 & 1639.25 & 355.18 & 11.33 & $150(36)$ & $3(3)$ & 38 \\
\hline & & M4 & 0 & 0 & 1741.64 & 1426.12 & 0 & 597.49 & 9.72 & $300(75)$ & $3(3)$ & 75 \\
\hline
\end{tabular}


Table 3. Parameters of pumped storage units.

\begin{tabular}{ccccccc}
\hline $\begin{array}{c}\text { Unit } \\
\text { Capacity/MW }\end{array}$ & $\begin{array}{c}\text { Number of } \\
\text { Units }\end{array}$ & $\begin{array}{c}\text { Power } \\
\text { Generation } \\
\text { Start-up Cost/\$ }\end{array}$ & $\begin{array}{c}\text { Pumping } \\
\text { Start-up } \\
\text { Cost/\$ }\end{array}$ & $\begin{array}{c}\text { Output Upper } \\
\text { (Lower) } \\
\text { Limit/MW }\end{array}$ & $\begin{array}{c}\text { Pumping } \\
\text { Power/MW }\end{array}$ & $\begin{array}{c}\text { Unit } \\
\text { Efficiency }\end{array}$ \\
\hline 300 & 3 & 313.43 & 313.43 & $300(100)$ & 300 & $80 \%$ \\
\hline
\end{tabular}

Table 4. Parameters of nuclear power units.

\begin{tabular}{|c|c|c|c|c|}
\hline \multirow{2}{*}{ Unit Capacity/MW } & \multirow{2}{*}{ Number of Units } & \multicolumn{2}{|c|}{ Operation Cost Coefficient } & \multirow{2}{*}{$\begin{array}{c}\text { Peak Shaving Fuel } \\
\text { Cost } /(\$ /(M W \cdot h))\end{array}$} \\
\hline & & $\mathrm{a} /(\$ / \mathrm{h})$ & $\mathrm{b} /(\$ /(M W \cdot h))$ & \\
\hline 900 & 2 & 6882.99 & 9.75 & 2.72 \\
\hline 1000 & 1 & 7647.76 & 9.75 & 2.72 \\
\hline $\begin{array}{c}\text { Unit } \\
\text { Capacity/MW }\end{array}$ & $\begin{array}{c}\text { Peak Shaving } \\
\text { Safety } \\
\text { Cost/(\$/(MW·h)) }\end{array}$ & $\begin{array}{c}\text { Output Upper } \\
\text { (Lower) Limit/MW }\end{array}$ & $\begin{array}{l}\text { Minimum Low } \\
\text { Power Duration/h }\end{array}$ & $\begin{array}{l}\text { Minimum Full } \\
\text { Power Duration/h }\end{array}$ \\
\hline 900 & 6.61 & $900(270)$ & 6 & 6 \\
\hline 1000 & 6.61 & $1000(300)$ & 6 & 6 \\
\hline
\end{tabular}

Figure 1 shows the day-ahead short-term forecast output of offshore wind farm and Figure 6 shows the typical daily load curve of the coastal province in summer. To simplify the calculation, it is assumed that the output of onshore wind farm is synchronized with that of the offshore wind farm and the unit installed output is 0.9 times of that of the offshore wind farm. Referring to the statistics of the International Renewable Energy Agency and the benchmark price of wind power, the cost of onshore wind power abandonment $p_{\mathrm{W}, \text { on }}$ is $51 \$ /(\mathrm{MW} \cdot \mathrm{h})$ and the cost of offshore wind power abandonment $p_{\mathrm{W}, \text { off }}$ is $76 \$ /(\mathrm{MW} \cdot \mathrm{h})$ [27-29]. The safety value coefficient of nuclear power is 1.5 , the maximum peak shaving depth of nuclear power is $70 \% \bar{P}_{\mathrm{e}}^{\mathrm{N}}$ and the peak shaving depth is subdivided into 100 grades. Load reserve coefficient $L_{\mathrm{u}} \%, L_{\mathrm{d}} \%$ are both $5 \%$ and wind power reserve coefficient $W_{\mathrm{u}, \text { on }} \%, W_{\mathrm{u}, \text { off }} \%$, $W_{\mathrm{d}, \text { on }} \%, W_{\mathrm{d}, \text { off }} \%$ are all taken as $15 \%$.

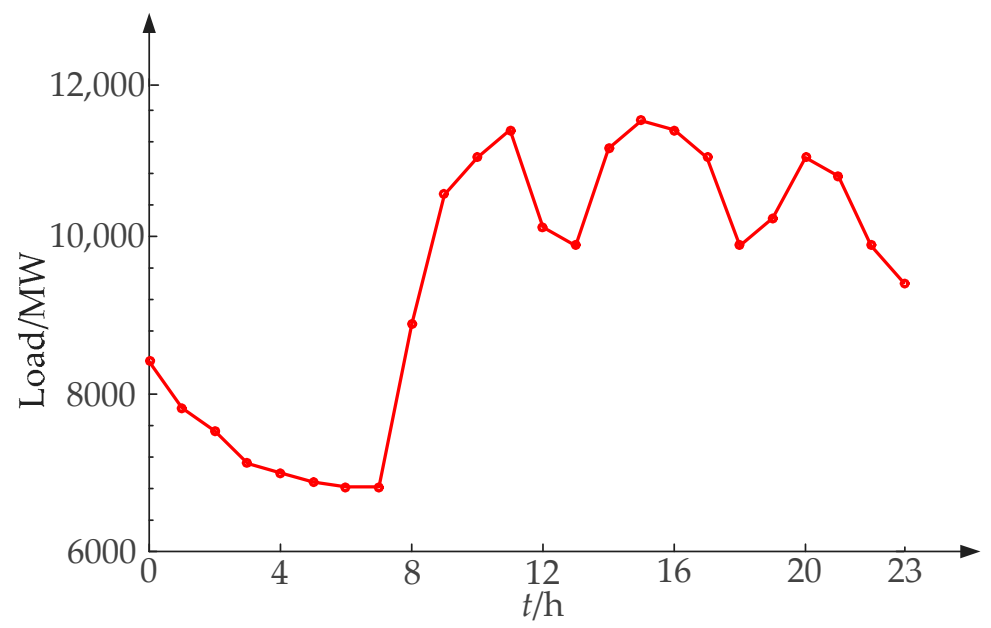

Figure 6. Daily load curve.

The simulation is based on the programming operation of Matlab-Yalmip-Cplex, the relative gap value of Cplex solver is 0.0001 by default. The computer is configured with an intel quad-core $2.5 \mathrm{GHz}$ processor and 4 GB memory.

\subsection{Matching Characteristics Analysis of Peak Shaving between Wind and Nuclear Power}

In order to analyze the matching characteristics between wind power and nuclear power peak shaving, the following three dispatching scenes are set. 
(a) Scene 1. The predicted output of wind power has the characteristics of positive peak shaving. The offshore wind power output is the positive peak shaving output in Figure 1.

(b) Scene 2. The predicted output of wind power has the characteristic of negative peak shaving. The offshore wind power output is multiplied by 0.5 of the negative peak shaving output in Figure 1 .

(c) Scene 3. The predicted output of wind power has the characteristics of strong negative peak shaving and the offshore output is the negative peak shaving output in Figure 1.

Table 5 is the optimization results of three kinds of dispatching scenes. It can be seen that scenes 1 and 2 can achieve economic dispatching without abandoning wind or nuclear power. This is because wind power presents positive or weak negative peak shaving characteristics and the peak shaving pressure of the system is small. Conventional units (coal-fired units, combined cycle units and pumped storage units) can meet the peak shaving requirements. In scene 3 , both wind power and nuclear power are involved in peak shaving. This is because wind power presents strong negative peak shaving characteristics, which increases the peak-valley difference of the equivalent load of the system and the peak shaving capacity of conventional units is insufficient. Therefore, nuclear power is required to reduce peak shaving power and abandon a small amount of wind power during low load period, so as to avoid frequent start-stop of conventional units and the operation economy is poor.

Table 5. Optimization results of 3 dispatching scenes.

\begin{tabular}{ccccccc}
\hline \multirow{2}{*}{ Scene } & \multicolumn{2}{c}{ Abandoned Power/(MW-h) } & \multicolumn{3}{c}{ Number of Start-Stop } \\
\cline { 2 - 7 } & $\begin{array}{c}\text { Onshore } \\
\text { Wind Farm }\end{array}$ & $\begin{array}{c}\text { Offshore } \\
\text { Wind Farm }\end{array}$ & $\begin{array}{c}\text { Nuclear } \\
\text { Power }\end{array}$ & $\begin{array}{c}\text { Coal-Fired } \\
\text { Units }\end{array}$ & $\begin{array}{c}\text { Combined } \\
\text { Cycle Units }\end{array}$ & $\begin{array}{c}\text { Pumped Storage } \\
\text { Units }\end{array}$ \\
\hline 1 & 0 & 0 & 0 & 0 & 0 & 3 \\
2 & 0 & 0 & 0 & 0 & 0 & 4 \\
3 & 19.93 & 0 & 3864.70 & 0 & 0 & 4 \\
\hline
\end{tabular}

It can be seen that only when the negative peak shaving characteristics of wind power reach a certain degree, the power reduction of nuclear power is required to participate in daily peak shaving, thus avoiding frequent participation of nuclear power units in daily peak shaving and realizing the economic dispatching of the system.

In addition, for nuclear power peak shaving in scene 3, according to the solving flow of Figure 5, if $1000 \mathrm{MW}$ nuclear power unit is designated to peak shaving, the day-ahead output plan of three nuclear power units can be determined as shown in Figure 7.

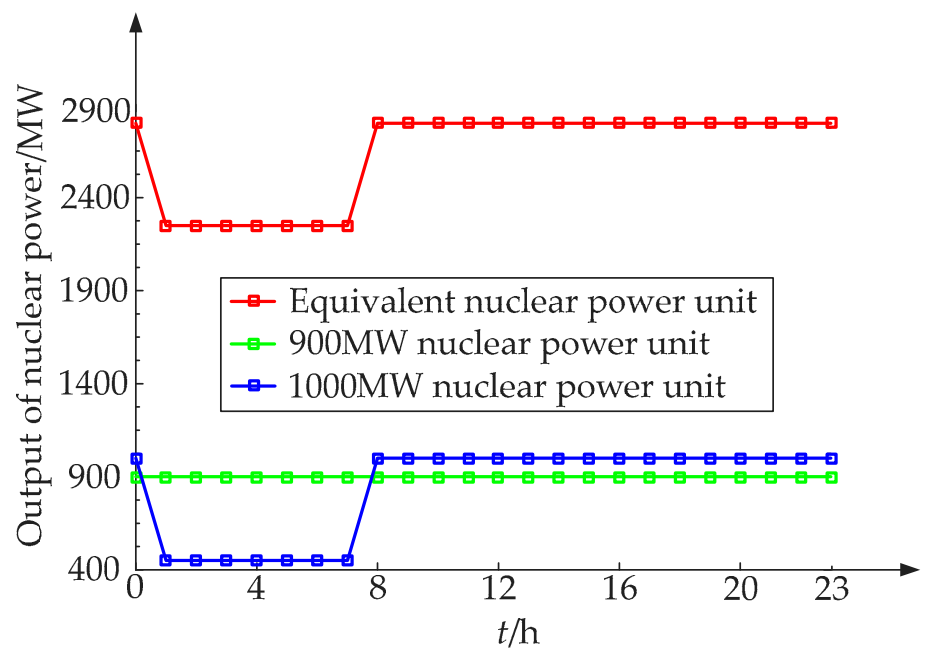

Figure 7. Output plan of nuclear power unit. 


\subsection{Effect of the Dispatching Model on Operation Economy}

The following four dispatching models are set up to compare and analyze the economy of the proposed dispatching model based on scene 3 .

(a) Model 1: Nuclear power units operate with base load and no wind abandonment is allowed.

(b) Model 2: Nuclear power units operate with base load and wind abandonment is allowed.

(c) Model 3: Nuclear power units can participate in peak shaving in daily load tracking mode and no wind abandonment is allowed.

(d) Model 4: Nuclear power units can participate in peak shaving in daily load tracking mode and wind abandonment is allowed, that is the dispatching model proposed in this paper.

Except for the differences mentioned above, the objective functions and other related constraints of the four dispatching models are the same and the optimization results are shown in Table 6, Figures 8 and 9.

Table 6. Optimization results of 4 scheduling models.

\begin{tabular}{|c|c|c|c|c|c|c|}
\hline Model & \multicolumn{2}{|c|}{ Total Operation Cost $/ 10^{3} \$$} & \multicolumn{2}{|c|}{$\begin{array}{c}\text { Abandoned Power } \\
\text { Cost } / 10^{3} \$\end{array}$} & \multicolumn{2}{|c|}{ Start-Stop Cost $/ 10^{3} \$$} \\
\hline 1 & \multicolumn{2}{|c|}{4284.07} & \multicolumn{2}{|c|}{0.00} & \multicolumn{2}{|c|}{215.12} \\
\hline 2 & \multicolumn{2}{|c|}{4235.42} & \multicolumn{2}{|c|}{110.37} & \multicolumn{2}{|c|}{17.06} \\
\hline 3 & \multicolumn{2}{|c|}{4153.36} & \multicolumn{2}{|c|}{49.97} & \multicolumn{2}{|c|}{5.55} \\
\hline 4 & \multicolumn{2}{|c|}{4149.49} & \multicolumn{2}{|c|}{51.22} & \multicolumn{2}{|c|}{0.94} \\
\hline \multirow[b]{2}{*}{ Model } & \multicolumn{3}{|c|}{ Abandoned Power/(MW·h) } & \multicolumn{3}{|c|}{ Number of Start-Stop } \\
\hline & $\begin{array}{c}\text { Onshore } \\
\text { Wind Farm }\end{array}$ & $\begin{array}{l}\text { Offshore } \\
\text { Wind Farm }\end{array}$ & $\begin{array}{l}\text { Nuclear } \\
\text { Power }\end{array}$ & $\begin{array}{l}\text { Coal-Fired } \\
\text { Units }\end{array}$ & $\begin{array}{l}\text { Combined } \\
\text { Cycle Units }\end{array}$ & $\begin{array}{c}\text { Pumped } \\
\text { Storage Units }\end{array}$ \\
\hline 1 & 0 & 0 & 0 & 4 & 8 & 3 \\
\hline 2 & 2162.39 & 0 & 0 & 1 & 4 & 3 \\
\hline 3 & 0 & 0 & 3978.8 & 0 & 2 & 3 \\
\hline 4 & 18.84 & 0 & 3978.8 & 0 & 0 & 3 \\
\hline
\end{tabular}

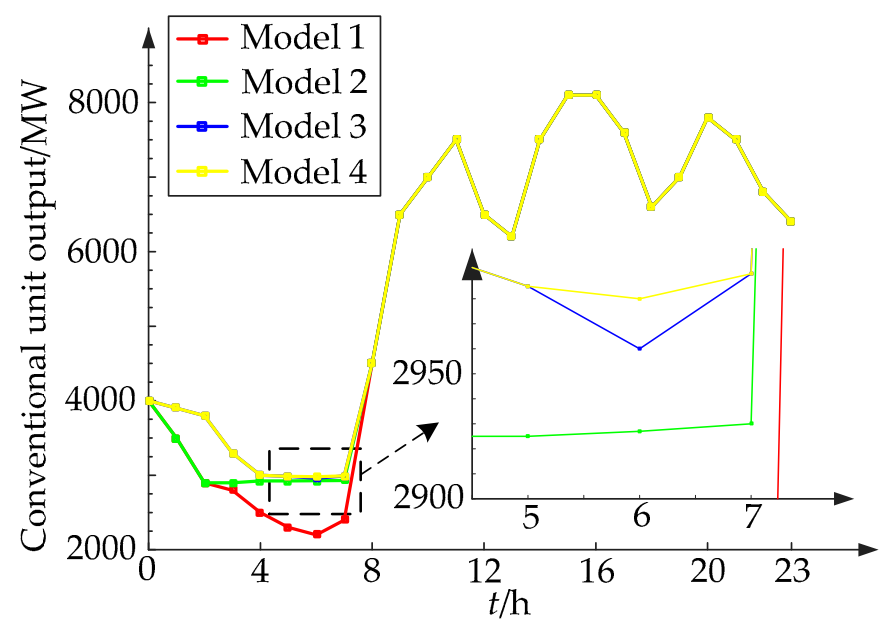

Figure 8. Power output of conventional units. 


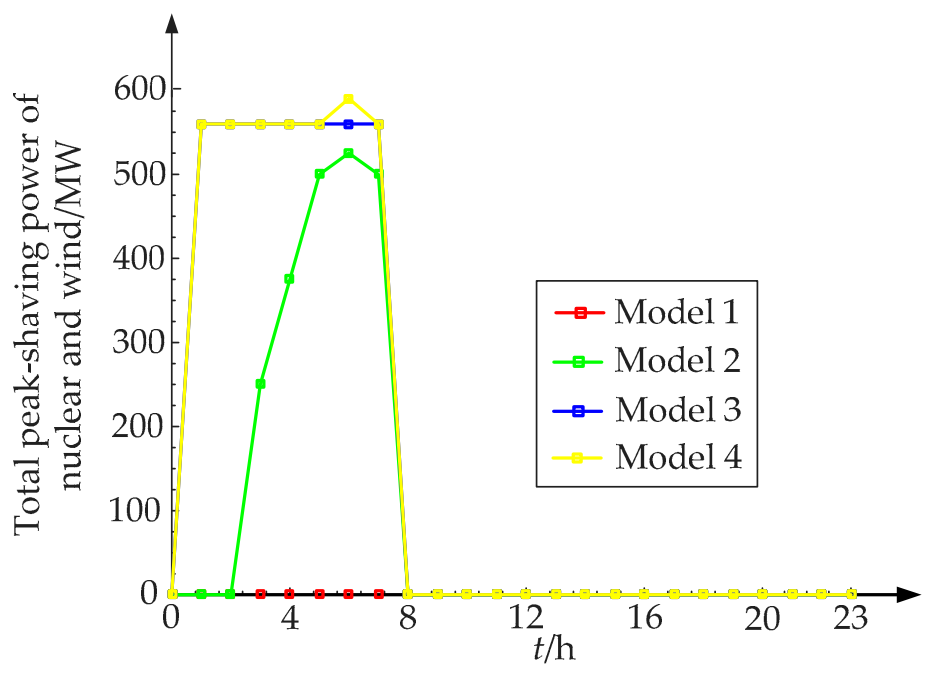

Figure 9. Total peak shaving power of nuclear power units and wind farm.

From Table 6 and Figure 8, it can be seen that with the participation of wind power and nuclear power in peak shaving, the peak shaving pressure of conventional units is reduced, frequent start-stop of conventional units are avoided, thus greatly reducing start-stop costs. Compared with model 1 , the total operation cost of model 2 and model 3 decreased by 48,650\$ and 130,710\$ respectively, which improved the operation economy. In addition, due to the high cost of wind abandonment per unit of electricity, the cost of model 2 is significantly higher than that of model 3, so the wind abandonment should be avoided as much as possible.

By comparing the optimization results of model 2, model 3 and model 4 , we can see that the operation economy is-model $4>$ model $3>$ model 2 . Combining with the analysis of Figure 9, model 2 has the characteristics of flexible peak-shaving ability but the cost of abandoning wind is high. Model 3 is constrained by its own operation safety and its output at low power stage needs to be constant but it has the advantage of low cost of abandoning nuclear. Model 4 combines the advantages of model 2 and model 3, the output of conventional units in low load period is raised and zero start-stop of coal-fired units and gas-steam combined cycle units are realized, thus further improving the operation economy.

It can be seen that wind-nuclear coordinated peak shaving reduces the pressure of conventional units, avoids frequent start-stop of conventional units. Also, coordinated dispatching of wind and nuclear power units can take into account peak shaving flexibility and cost, improve dispatching economy of wind power and nuclear power systems and reduce wind abandonment.

It should be noted that, due to the cost coefficient of abandoned electricity-offshore wind power $>$ onshore wind power $>$ nuclear power, under the scenario of strong negative peak-shaving of wind power, the coordinated dispatching of wind power and nuclear power is mainly undertaken by nuclear power, while the onshore wind power takes little and the offshore wind power does not. Abandoning electricity and peak shaving will damage the benefits of various interests, so it is necessary to develop a reasonable peak shaving compensation mechanism to achieve a balance among various interests.

\subsection{Effect of Daily Peak Shaving Mode on the Dispatching Optimization Results}

The following four modes are set for simulation and comparison.

(a) Mode 1: Nuclear power units are operated with base load and do not participate in daily peak shaving.

(b) Mode 2: Nuclear power unit participates in daily peak shaving with 100 MW out-pressure (the intraday output power is constant but not full).

(c) Mode 3: Nuclear power units use three fixed peak shaving depths for daily load tracking and peak shaving [43]. 
(d) Mode 4: The mode proposed in this paper-the precise optimization of peak shaving is realized by subdividing the peak-shaving depth of nuclear power.

Assuming that two $900 \mathrm{MW}$ nuclear power units have recently participated in daily peak shaving, 1000 MW nuclear power units are designated as peak shaving units. The results of dispatching optimization based on scene 3 are shown in Table 7 and Figure 10.

Table 7. Optimization results of 4 peak shaving modes.

\begin{tabular}{|c|c|c|c|c|c|c|}
\hline Mode & \multicolumn{3}{|c|}{ Total Operation Cost $/ 10^{3} \$$} & \multicolumn{2}{|c|}{$\begin{array}{c}\text { Abandoned Power } \\
\text { Cost } / 10^{3} \$\end{array}$} & $\begin{array}{l}\text { Start-Stop } \\
\text { Cost } / 10^{3} \$\end{array}$ \\
\hline 1 & \multicolumn{3}{|c|}{4235.42} & \multicolumn{2}{|c|}{110.37} & 17.06 \\
\hline 2 & \multicolumn{3}{|c|}{4258.31} & \multicolumn{2}{|c|}{130.12} & 22.33 \\
\hline 3 & \multicolumn{3}{|c|}{4155.97} & \multicolumn{2}{|c|}{45.70} & 10.16 \\
\hline 4 & \multicolumn{3}{|c|}{4149.49} & \multicolumn{2}{|c|}{51.22} & 0.94 \\
\hline \multirow[b]{2}{*}{ Mode } & \multicolumn{3}{|c|}{ Abandoned Power/(MW·h) } & \multicolumn{3}{|c|}{ Number of Start-Stop } \\
\hline & $\begin{array}{l}\text { Onshore } \\
\text { Wind Farm }\end{array}$ & $\begin{array}{l}\text { Offshore } \\
\text { Wind Farm }\end{array}$ & $\begin{array}{l}\text { Nuclear } \\
\text { Power }\end{array}$ & $\begin{array}{l}\text { Coal-Fired } \\
\text { Units }\end{array}$ & $\begin{array}{l}\text { Combined } \\
\text { Cycle Units }\end{array}$ & $\begin{array}{c}\text { Pumped } \\
\text { Storage Units }\end{array}$ \\
\hline 1 & 2162.39 & 0 & 0 & 1 & 4 & 3 \\
\hline 2 & 1954.89 & 0 & 2400 & 1 & 8 & 3 \\
\hline 3 & 28.79 & 0 & 3500 & 1 & 2 & 3 \\
\hline 4 & 18.84 & 0 & 3978.8 & 0 & 0 & 3 \\
\hline
\end{tabular}

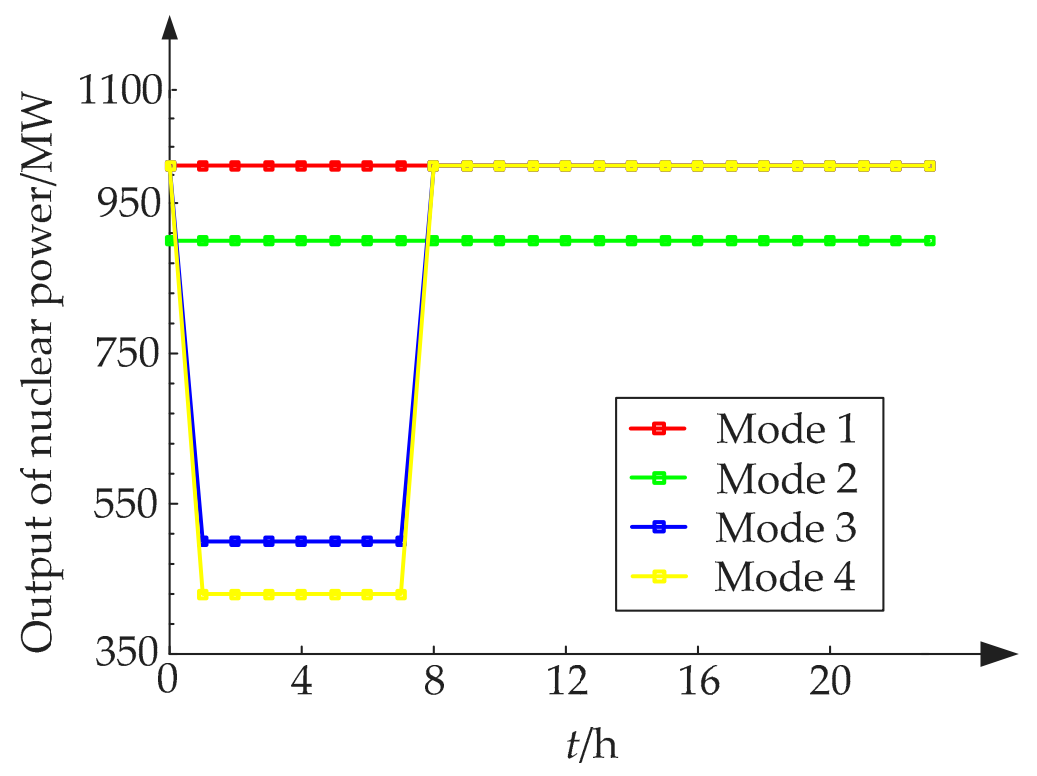

Figure 10. Output of nuclear power of 4 peak shaving modes.

From Table 7, it can be seen that mode 1 will cause a large amount of wind abandonment and the start-stop of conventional units are relatively frequent, resulting in high operation costs. Mode 2 reduces the amount of abandoned wind power but does not reduce the cost of power abandonment and causes the number of start-stop of combined cycle units to increase, which in turn increases the total operation cost. Both mode 3 and mode 4 greatly reduce the amount of abandoned wind power and the cost of it and mode 4 has the lowest total operation cost because it does not require the coal-fired units and combined cycle units to start-up and shutdown.

As shown in Figure 10, in mode 2, although the downward peak-shaving pressure has been alleviated during the low load period, the upward peak-shaving pressure during the high load period has been increased due to the inability to track the daily load change, which increases the number of start-stop of combined cycle units and reduces the operation economy. In mode 3, the nuclear power output tracks daily load change, avoids the defect of mode 2 and reduces operation costs. However, 
due to the use of fixed peak shaving depth, it is not possible to accurately optimize the output of nuclear power units during low-power stage, which easily leads to "undershoot" or "overshoot" of nuclear power, so the operation economy is not as good as that of mode 4 .

It can be seen that the nuclear power unit adopts the daily load tracking mode to participate in the daily peak shaving and precisely optimizes the nuclear power peak shaving depth, which can effectively reduce the total operation cost. At the same time, with the increase of peak shaving grade, the operation cost of the system tends to be optimal, so as to realize the precise optimization of peak shaving for nuclear power.

In addition, due to the uncertainty of wind power output, the peak shaving of the power grid requires that each unit has a certain rapid response time. For large coal-fired thermal power units at home and abroad, the average climbing rate is $2.5 \sim 5 \% P_{\mathrm{n}} / \mathrm{min}$. For gas-combined cycle units, the start-up and shutdown time is faster. A Simple gas cycle can achieve $100 \%$ load rise and fall within $12 \mathrm{~min}$. For pumped storage power station, it only takes $2 \sim 4 \mathrm{~min}$ from static state to full-load power generation and only $3 \sim 4 \mathrm{~min}$ from emergency state to full-load state. For nuclear power units, such as AP1000, the following transient conditions can be satisfied in design: (i) linear load change of $\pm 5 \%$ $P_{\mathrm{n}} / \mathrm{min}$ and step load change of $\pm 10 \% P_{\mathrm{n}}$ in the range of $15-100 \% P_{\mathrm{n}}$. (ii) The power step of $20 \% P_{\mathrm{n}}$ increase or decrease within $10 \mathrm{~min}$. (iii) $2 \% P_{\mathrm{n}} / \mathrm{min}$ rate and $10 \% P_{\mathrm{n}}$ peak power change are adapted to frequency change of the power grid. In this paper, the climbing rate of each unit is considered in the constraints of the scheduling strategy, which can meet the scheduling requirements.

Figure 11 shows the dispatching output curve of 28 coal-fired units in Mode 4 . It can be seen that during the period of rapid decline/rise of payload (load minus wind power), the output of conventional units such as coal-fired unit changes as quickly as possible (as shown in Figure 11, 390 MW units climb at the maximum rate) and provide the reserve capacity to meet the system requirement. Due to the limited peak-shaving capacity of conventional units and the largest proportion of coal-fired units participating in peak-shaving will increase the dispatching cost, the remaining required power adjustment is borne by nuclear power units, which operate in the "15-1-7-1" mode of daily load tracking.

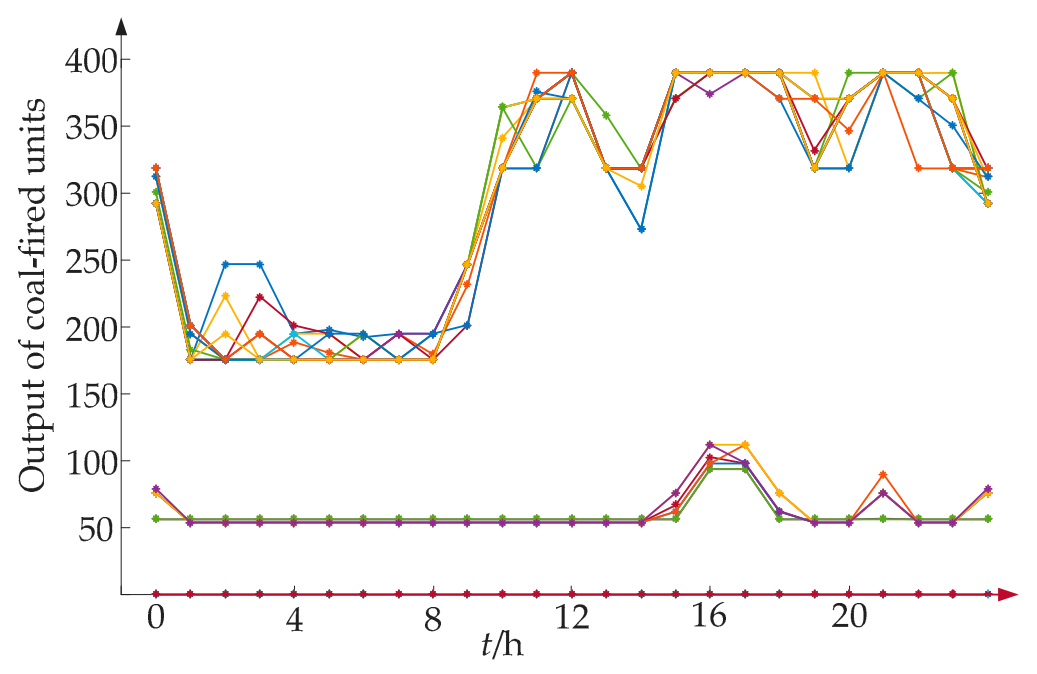

Figure 11. Output of coal-fired units in mode 4.

Therefore, the large-scale access of wind power and the increase of peak-valley load difference increase the peak-shaving pressure of the power grid and the daily load tracking operation of nuclear power is required due to the safety and operation economy of the power grid.

\subsection{Analysis of Abandoned Wind Cost Coefficient}

In the above example analysis, $p_{\mathrm{W}, \text { on }}$ and $p_{\mathrm{W}, \text { off }}$ take 51 and 76 respectively. However, the selection of abandoned wind cost coefficient should reflect the life cycle cost of wind power investment and 
operation. With the maturity of technology such as wind turbine equipment manufacturing, operation and maintenance, the life cycle cost of wind power will gradually decrease and the cost coefficient of wind abandonment will also decrease. This paper introduces the abandoned wind cost coefficient factors $k_{\mathrm{W} \text {, on }}, k_{\mathrm{W}, \text { off }}$ to describe the change of abandoned wind cost coefficient: $p^{\prime}{ }_{\mathrm{W} \text {,on }}=k_{\mathrm{W}, \text { on }} p_{\mathrm{W} \text {,on }}$

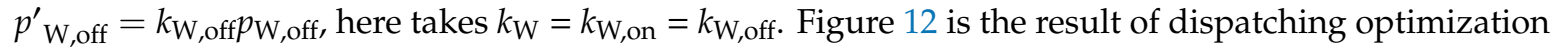
under different abandoned wind cost coefficients.

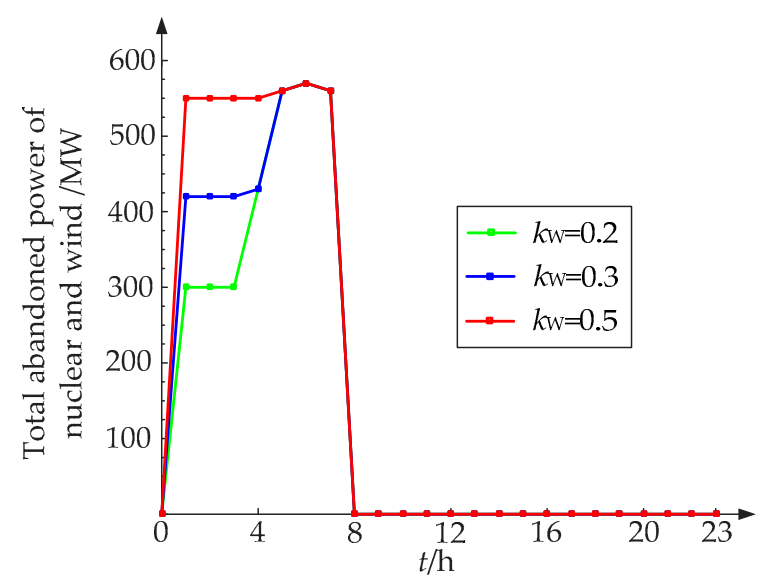

(a)

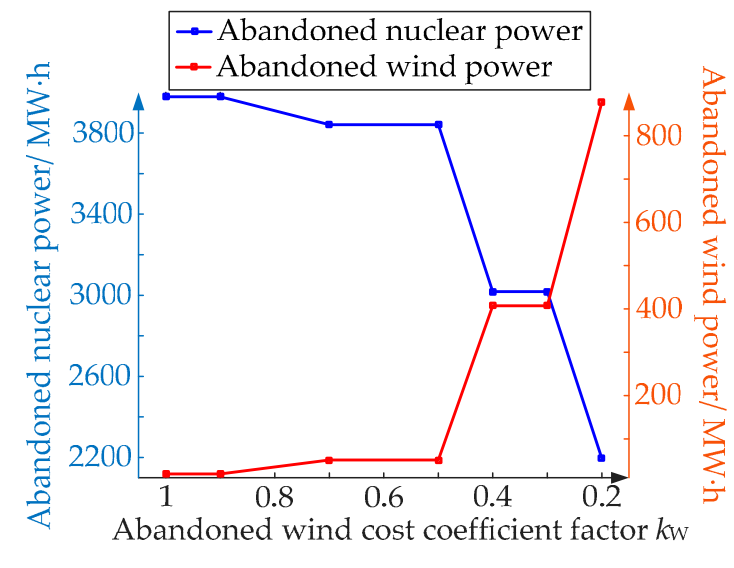

(b)

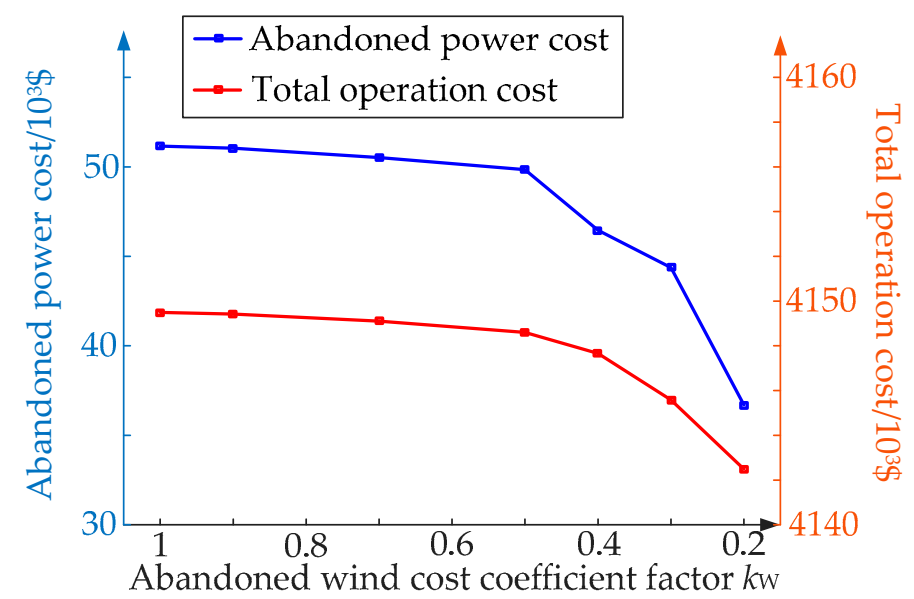

(c)

Figure 12. Dispatching optimization results under different abandoned wind cost coefficient factors: (a) Total abandoned power, (b) Abandoned nuclear and wind power and (c) Abandoned power cost and total operation cost.

As shown in Figure 12a, with the decrease of the abandoned wind cost coefficient, the peak shaving power of nuclear will decrease and the abandoned wind power will increase in more periods. For example, during ' $4 \mathrm{~h} \sim 7 \mathrm{~h}$,' the abandoned wind power is $[0,8.86,32.44,9.83]$ (the unit is MW, the same below) when $k_{\mathrm{W}}$ is $0.5,[3.39,126.46,150.04,127.43]$ when $k_{\mathrm{W}}$ is 0.3 and $[120.99,244.06,267.64$, 245.03] when $k_{\mathrm{W}}$ is 0.2 . This is because the nuclear power peak shaving is restricted by safety, so the nuclear power cannot be adjusted at will. During low power period, it is necessary for nuclear power units to maintain constant output for a certain period of time. As the cost coefficient of wind power abandonment decreases, more nuclear power abandonment can be avoided by increasing the wind abandonment, as shown in Figure 12b, which is beneficial to reduce the peak shaving cost of power abandonment, thereby improving the operation economy, as shown in Figure 12c. 
In addition, when the abandoned wind cost coefficient is large, since the peak shaving of nuclear power is more economical, the peak shaving of abandoned power is basically undertaken by the nuclear power units and the variation of peak shaving power is very small. So, when the $k_{\mathrm{W}}$ is reduced from 1.0 to 0.5 , the abandoned power, the abandoned power cost and the total operation cost all decrease slowly. When the abandoned wind cost coefficient is small, due to the flexibility of wind power peak shaving, abandoning the wind power for peak shaving presents economy. As a result, the abandoned wind power increased significantly and the abandoned nuclear power decreased significantly. When the $k_{\mathrm{W}}$ dropped from 0.5 to 0.2 , the abandoned power cost and the total operation cost decreased faster.

It can be seen that with the development of technology such as wind turbine equipment manufacturing, operation and maintenance, the cost coefficient of wind power abandonment decreases. In the wind-nuclear coordinated dispatching, wind power can coordinate with nuclear power more fully with its peak shaving flexibility, which will effectively promote the economic dispatching of the power system.

\section{Conclusions}

In this paper, the matching characteristic between the output of wind power and nuclear power is analyzed. Considering power abandonment cost and peak shaving cost, a multi-power joint peak-shaving model considering coordinated dispatching of nuclear and wind power is established and a method of subdividing the peak shaving depth is proposed to linearize the constraints of nuclear power peak shaving. The proposed model and method are analyzed with a regional power system. The main conclusions are as follows:

- Wind power output matches the peak shaving characteristics of nuclear power. Only when the negative peak-shaving characteristic of wind power reaches a certain degree can nuclear power be required to participate in daily peak-shaving, thus avoiding frequent participation of nuclear power units in daily peak-shaving and realizing the economic dispatching of the system.

- Participation of wind and nuclear in peak shaving can reduce peak shaving pressure of conventional units, avoid frequent start-stop of conventional units and coordinated dispatching of wind and nuclear units can take into account peak shaving flexibility and cost, improve dispatching economy of the power system and reduce wind abandonment.

- Daily load tracking mode is used to participate in daily peak shaving for nuclear power units and the method of subdividing the depth of peak shaving is used to accurately optimize the output of nuclear power, which can effectively reduce the total operation cost of the system.

- With the development of wind power technology, the abandoned wind cost is getting smaller and smaller. The cooperation between wind power and nuclear power can reduce the pressure of nuclear power plant for peak-shaving demand of the power system and promote the operation economy.

In the follow-up work, the environmental economic dispatching and peak shaving compensation mechanism for power system including wind and nuclear power will be further studied.

Author Contributions: The authors confirm their contributions to the paper as follows: Q.L. and J.Z. proposed the idea and wrote the paper; D.L., J.W. and Y.S. revised the manuscript; Y.M. and L.W. reviewed the results and approved the final version of the manuscript.

Funding: This study was funded by the National Natural Science Foundation of China (grant number 51677137) and Fundamental Research Funds for the Central Universities (grant number 2042018kf0051).

Acknowledgments: We sincerely thank the editor and the anonymous reviewers of the paper for their kind support. We also want to thank to the Grid Corporation for providing relevant information and data.

Conflicts of Interest: The authors declare no conflict of interest. 


\section{Nomenclature}

\section{Parameters}

$n_{\mathrm{T}}, n_{\mathrm{CC}}, n_{\mathrm{W}, \mathrm{on}}, n_{\mathrm{W}, \mathrm{off}}$

$n_{\mathrm{N}}, n_{\mathrm{PS}}$

$M_{\mathrm{CC}}, M_{\mathrm{CC}}^{y}$

$a_{i}^{\mathrm{T}}, b_{i}^{\mathrm{T}}, c_{i}^{\mathrm{T}}$

$a_{i, y}^{\mathrm{CC}}, b_{i, y}^{\mathrm{CC}}$

$a_{\mathrm{e}}^{\mathrm{N}}, b_{\mathrm{e}}^{\mathrm{N}}$

$a_{i}^{\mathrm{N}}, \bar{P}_{i}^{\mathrm{N}}$

$s_{i, \text { start }}{ }^{\mathrm{T}} s_{i \text {,stop }}^{\mathrm{T}}$

$p_{\mathrm{W}, \mathrm{on}}, p_{\mathrm{W}, \mathrm{off}}$

$\Delta E_{\mathrm{W}, \mathrm{on}}, \Delta E_{\mathrm{W}, \mathrm{off}}$

$p_{\mathrm{N}}$

$p_{\mathrm{N}, \mathrm{f}}$

$p_{\mathrm{N}, \mathrm{s}}$

$\sigma$

$R_{\mathrm{u}, t}, R_{\mathrm{d}, t}$

$L_{\mathrm{u}} \%, W_{\mathrm{u}, \mathrm{on}} \%, W_{\mathrm{u}, \mathrm{off}} \%$

$L_{\mathrm{d}} \%, W_{\mathrm{d}, \mathrm{on}} \%, W_{\mathrm{d}, \mathrm{off}} \%$

$\bar{P}_{i}^{\mathrm{T}}, \underline{P}_{i}^{\mathrm{T}}$

$r_{\mathrm{u}, i}^{\mathrm{T}}, r_{\mathrm{d}, i}^{\mathrm{T}}$

$T_{10}$

$\bar{P}_{i, y}^{\mathrm{CC}}, \underline{P}_{i, y}^{\mathrm{CC}}$

$h_{t}$

$l_{m, t}$

$q_{m, j, t}$

$\underline{T}_{h}^{\mathrm{N}}, \underline{T}_{l}^{\mathrm{N}}$

$P_{i, t}^{\mathrm{T}}, P_{i, t}^{\mathrm{PS}}, P_{i, t}^{\mathrm{CC}}$

$P_{i t}^{G}$

$\bar{P}_{i}^{i, t}, \underline{P}_{i}^{G}$

$V_{\mathrm{u}, t}, V_{\mathrm{d}, t}$

$\bar{V}_{\mathrm{u}}, \underline{V}_{\mathrm{u}}, \bar{V}_{\mathrm{d}}, \underline{V}_{\mathrm{d}}$

$P_{t}^{\mathrm{L}}$

$\underline{P}_{i, y}^{C C}, \Delta P_{i, t, y}^{C C}$

$P_{i, t}^{\mathrm{W} \text {,on,Pre }}, P_{i, t}^{\mathrm{W} \text {,on }}$

$P_{i, t}^{W, t}$,off,Pre,$P_{i, t}^{W, \text { off }}$

$P_{\mathrm{e}, t}^{\mathrm{N}}, \bar{P}_{\mathrm{e}}^{\mathrm{N}}$

${ }_{r} \stackrel{\mathrm{C}}{\mathrm{C}},{ }_{r} \mathrm{CC}$

${ }_{\mathrm{P}, i, y^{\prime}}^{\mathrm{G}}{ }_{\mathrm{P}}^{\mathrm{d}, i, y}$

$\bar{P}_{i}^{\mathrm{G}}, \bar{P}_{i}^{\mathrm{P}}$

$\underline{T}_{\text {on }, i^{\prime}}^{\mathrm{T}} \underline{T}_{\mathrm{off}, i}^{\mathrm{T}}$ number of coal-fired units, gas-steam combined cycle units, onshore wind farms and offshore wind farms respectively

number of nuclear power units and pumped storage units

all mode sets of combined cycle units and modes that can be transformed in $y$

mode

fuel cost coefficient of coal-fired unit $i$

gas cost coefficient of combined cycle unit $i$ in $y$ mode

operation cost constant of the equivalent nuclear power unit $\mathrm{U}_{\mathrm{e}}^{\mathrm{N}}$ and the cost

coefficient of nuclear fuel

operation cost constant term and the rated output of the nuclear power unit $i$

cost of generating electricity and pumping water for pumped storage unit $i$

cost coefficient of wind power abandonment on land and offshore

abandoned onshore and offshore wind power respectively

peak shaving cost coefficient of nuclear power

fuel cost coefficient of nuclear power peak shaving

safety cost coefficient of nuclear power peak shaving

nuclear power safety value coefficient which balances nuclear power peak

shaving safety and economy

positive and negative spinning reserve capacity of the system during $t$ period

positive spinning reserve coefficient for load, onshore wind power and offshore

wind power, respectively

negative spinning reserve coefficient for load, onshore wind power and offshore

wind power, respectively

maximum and minimum technical output of the coal-fired unit $i$

increasing and falling climbing rates of coal-fired unit $i$

spinning reserve response time, here takes $10 \mathrm{~min}$

maximum and minimum technical output of combined cycle unit $i$ in $y$ mode

rated power operation mark of nuclear power unit at $t$ time

low power operation mark of the nuclear power unit under the $m$-th grade peak shaving depth at $t$ time

operation mark for power up (or down) of the nuclear power unit under the $m$-th grade peak shaving depth at $t$ time

full-power minimum continuous running time and low-power minimum

continuous running time of nuclear power respectively

output of coal-fired unit $i$, pumped storage unit $i$ and combined cycle unit $i$

during $t$ period

power generation dispatching output of the pumped storage unit $i$

upper and lower limit of $P_{i, t}^{G}$

storage capacity of the upper and lower reservoir at $t$ time

upper and lower limit of $V_{\mathrm{u}, t}$ and $V_{\mathrm{d}, t}$, respectively

the system load at $t$ time

minimum technical output of combined cycle unit $i$ in $y$ mode and the output of higher than $\underline{P}_{i, y}^{C C}$ during $t$ period

the predictive and dispatching output of the $i$-th onshore wind farm respectively the predictive and dispatching output of the $i$-th offshore wind farm respectively dispatching output and rated output of the nuclear power unit increasing and falling climbing rate of combined cycle unit $i$ in $y$ mode maximum generating power and fixed pumping power of pumped storage unit $i$ the minimum running time and the minimum downtime of coal-fired unit $i$ 


$r_{\mathrm{u}, i, z y^{\prime}}^{\mathrm{CC}} r_{\mathrm{d}, i, y z}^{\mathrm{CC}}$
$\underline{T}_{\mathrm{on}, i, y^{\prime}}^{\mathrm{CC}} \underline{T}_{\mathrm{off}, i, y}^{\mathrm{CC}}$
$P_{\mathrm{e}}^{\mathrm{N}}$
Variables
$\mathrm{C}$
$C_{\mathrm{T}}, C_{\mathrm{CC}}, C_{\mathrm{Nuc}}, C_{\mathrm{PS}}$
$s_{i, y z}^{\mathrm{CC}}$
$u_{i, t, y}^{\mathrm{CC}}$
$v_{i, t, y z}^{\mathrm{CC}}$
$\alpha_{i, t}^{\mathrm{P}}$
$u_{i, t}^{\mathrm{p}}$
$C_{\text {Wind }}$
$S_{i, t}^{\mathrm{T}}$
$u_{i, t}^{\mathrm{T}}$
$\alpha_{i, t}^{\mathrm{T}} \beta_{i, t}^{\mathrm{T}}$
$\alpha_{i, t}^{\mathrm{G}}$
$u_{i, t}^{\mathrm{g}}$

increasing and falling climbing rates of combined cycle unit $i$ during mode conversion, respectively minimum running time and minimum downtime of combined cycle unit $i$ in $y$ mode minimum output allowed by the equivalent nuclear power unit

total operation cost operation cost of coal-fired units, gas-steam combined cycle units, nuclear power units and pumped storage units, respectively conversion cost of the combined cycle unit $i$ from mode $y$ to mode $z$ $0-1$ variable whose value is 1 when the combined cycle unit $i$ is running during $t$ period

$0-1$ variable whose value is 1 when combined cycle unit $i$ transforms from mode $y$ to mode $z$

$0-1$ variable whose value is 1 when pumped storage unit $i$ changes from power generation state to stop state during $t$ period

$0-1$ variable whose value is 1 when pumped storage unit $i$ is pumping water cost of wind power abandonment

start-stop cost of coal-fired units

$0-1$ variable whose value is 1 when the coal-fired unit $i$ is running during $t$ period $0-1$ variable indicating start-up and shut-down of coal-fired unit in $t$ period $0-1$ variable whose value is 1 when pumped storage unit $i$ changes from stop state to power generation state during $t$ period $0-1$ variable whose value is 1 when pumped storage unit $i$ is generating power

\section{References}

1. Ge, W.C.; Sun, P.; Li, J.J.; Zhang, T.; Zhang, Q.; Wang, C. Research on economic operation of multi-source peak-shaving involving nuclear power. In Proceedings of the 2018 International Conference on Smart Grid and Electrical Automation (ICSGEA), Changsha, China, 9-10 June 2018; pp. 46-49.

2. Feng, Z.-K.; Niu, W.-J.; Cheng, C.-T.; Zhou, J.-Z. Peak shaving operation of hydro-thermal-nuclear plants serving multiple power grids by linear programming. Energy 2017, 135, 210-219. [CrossRef]

3. Wang, C.; Lu, Z.; Qiao, Y. A Consideration of the Wind Power Benefits in Day-Ahead Scheduling of Wind-Coal Intensive Power Systems. IEEE Trans. Power Syst. 2013, 28, 236-245. [CrossRef]

4. Cany, C.; Mansilla, C.; Mathonnière, G.; Da Costa, P. Nuclear power supply: Going against the misconceptions. Evidence of nuclear flexibility from the French experience. Energy 2018, 151, 289-296. [CrossRef]

5. Li, H.; Lu, Z.; Qiao, Y.; Wang, W. Risk assessment of power system with high penetration of wind power considering negative peak shaving and extreme weather conditions. In Proceedings of the 2014 IEEE PES General Meeting|Conference \& Exposition, National Harbor, MD, USA, 27-31 July 2014; pp. 1-5.

6. Antenucci, A.; Sansavini, G. Gas-Constrained Secure Reserve Allocation with Large Renewable Penetration. IEEE Trans. Sustain. Energy 2018, 9, 685-694. [CrossRef]

7. Eliasi, H.; Menhaj, M.; Davilu, H. Robust nonlinear model predictive control for nuclear power plants in load following operations with bounded xenon oscillations. Nucl. Eng. Des. 2011, 241, 533-543. [CrossRef]

8. Lee, H.; Cha, W.C. Virtual Reality-Based Ergonomic Modeling and Evaluation Framework for Nuclear Power Plant Operation and Control. Sustainability 2019, 11, 2630. [CrossRef]

9. Chen, K.S.; Lin, K.P.; Yan, J.X.; Hsieh, W.L. Renewable Power Output Forecasting Using Least-Squares Support Vector Regression and Google Data. Sustainability 2019, 11, 3009. [CrossRef]

10. Kang, M.Y.; Jeong, Y.; Jung, Y. Assessment Methodology of Practical Configuration Management (CM) for Sustainable Nuclear Power Plants (NPPs). Sustainability 2019, 11, 2391. [CrossRef]

11. Kim, H.J.; Yu, J.J.; Yoo, S.H. Does Combined Heat and Power Play the Role of a Bridge in Energy Transition? Evidence from a Cross-Country Analysis. Sustainability 2019, 11, 1035. [CrossRef]

12. Zou, Y.; Zou, S.; Niu, C. The Optimization of Emergency Evacuation from Nuclear Accidents in China. Sustainability 2018, 10, 2737. [CrossRef] 
13. Kudiyarasan, S.; Sivakumar, P. Modern Analysis of Power Flow and Network Stability of Transmission Lines for Nuclear Power Dispatch. Int. J. Sci. Technol. Soc. 2019, 7, 21-32. [CrossRef]

14. Neyestani, M.; Farsangi, M. Optimization of the Economic Dispatch problem by considering the emission dispatch with using the AMPSO. Adv. Model. Anal. C 2018, 73, 60-71. [CrossRef]

15. Ciornei, I.; Kyriakides, E. Recent methodologies and approaches for the economic dispatch of generation in power systems. Int. Trans. Electr. Energy Syst. 2013, 23, 1002-1027. [CrossRef]

16. Dhillon, J.; Jain, S.K. Multi-Objective Generation and Emission Dispatch Using NSGA-II. Int. J. Eng. Technol. 2011, 3, 460-466. [CrossRef]

17. Gao, C.W.; Li, Y. Evolution of China's power dispatch principle and the new energy saving power dispatch policy. Energy Policy 2010, 38, 7346-7357.

18. Barcelo, W.; Rastgoufard, P. Dynamic economic dispatch using the extended security constrained economic dispatch algorithm. IEEE Trans. Power Syst. 1997, 12, 961-967. [CrossRef]

19. Abdelaziz, A.; Ali, E.; Elazim, S.A. Implementation of flower pollination algorithm for solving economic load dispatch and combined economic emission dispatch problems in power systems. Energy 2016, 101, 506-518. [CrossRef]

20. Khalid, M. Wind Power Economic Dispatch-Impact of Radial Basis Functional Networks and Battery Energy Storage. IEEE Access 2019, 7, 36819-36832. [CrossRef]

21. Basu, M. Multi-area dynamic economic emission dispatch of hydro-wind-thermal power system. Renew. Energy Focus 2019, 28, 11-35. [CrossRef]

22. Ha, C.H.; Kim, J.H.; Lee, S.J.; Seong, P.H. Investigation on relationship between information flow rate and mental workload of accident diagnosis tasks in NPPs. IEEE Trans. Nucl. Sci. 2006, 53, 1450-1459.

23. Aizpurua, J.I.; McArthur, S.D.J.; Stewart, B.G.; Lambert, B.; Cross, J.G.; Catterson, V.M.; Unanue, J.I.A. Adaptive Power Transformer Lifetime Predictions Through Machine Learning and Uncertainty Modeling in Nuclear Power Plants. IEEE Trans. Ind. Electron. 2019, 66, 4726-4737. [CrossRef]

24. Taljan, G.; Canizares, C.; Fowler, M.; Verbic, G. The Feasibility of Hydrogen Storage for Mixed Wind-Nuclear Power Plants. IEEE Trans. Power Syst. 2008, 23, 1507-1518. [CrossRef]

25. Shortt, A.; Kiviluoma, J.; O'Malley, M. Accommodating Variability in Generation Planning. IEEE Trans. Power Syst. 2013, 28, 158-169. [CrossRef]

26. Loisel, R.; Alexeeva, V.; Zucker, A.; Shropshire, D. Load-following with nuclear power: Market effects and welfare implications. Prog. Nucl. Energy 2018, 109, 280-292. [CrossRef]

27. Zhang, T.; Ma, X.D.; Zhu, Y.; Wang, G.; Ye, P. A Research Summary on Combined Peaking Load Strategies of Nuclear Power Plant. Adv. Mater. Res. 2014, 986, 196-201. [CrossRef]

28. Dong, Z.; Feng, J.; Huang, X. Nonlinear Observer-Based Feedback Dissipation Load-Following Control for Nuclear Reactors. IEEE Trans. Nucl. Sci. 2009, 56, 272-285. [CrossRef]

29. Ge, F.; Lin, Y.; Ju, Y.; Qi, Z. Unit commitment considering the characteristics of nuclear and wind power. In Proceedings of the 2018 International Conference on Power System Technology (POWERCON), Guangzhou, China, 6-8 November 2018; pp. 4765-4771.

30. Ma, C.; Jiang, Z.; Zhang, P.; Gao, W.; Liu, W. Economic analysis of wind power accommodation considering operation modes of nuclear power plants. In Proceedings of the IECON 2017—43rd Annual Conference of the IEEE Industrial Electronics Society, Beijing, China, 29 October-1 November 2017; pp. 2467-2472.

31. Hou, W.T.; Wei, H. A multi-source coordinated short-term dispatch model considering the dispatchability of nuclear power plants. Trans. China Electrotech. Soc. 2018, 33, 2873-2882.

32. Liu, W.Y.; Wen, J.; Xie, C.; Wang, W.; Liang, C. Multi-objective optimal method considering wind power accommodation based on source-load coordination. Proc. CSEE 2015, 35, 1079-1088.

33. Wang, Y.; Chen, H.; Xuan, P.; Hua, D. A robust scheduling with multiple types of power sources based on optimal scenario set. Power Syst. Technol. 2016, 40, 354-362.

34. Jiang, R.; Wang, J.; Guan, Y. Robust Unit Commitment with Wind Power and Pumped Storage Hydro. IEEE Trans. Power Syst. 2012, 27, 800-810. [CrossRef]

35. Meus, J.; Poncelet, K.; Delarue, E. Applicability of a Clustered Unit Commitment Model in Power System Modeling. IEEE Trans. Power Syst. 2018, 33, 2195-2204. [CrossRef]

36. Chen, Y.; Liu, F.; Liu, B.; Wei, W.; Mei, S. An Efficient MILP Approximation for the Hydro-Thermal Unit Commitment. IEEE Trans. Power Syst. 2016, 31, 3318-3319. [CrossRef]

37. EUR. The European Utility Requirement (EUR) Document; Revision C; EUR: Budapest, Hungary, 2001; Volume 2. 
38. Morales-Espana, G.; Correa-Posada, C.M.; Ramos, A. Tight and compact MIP formulation of configuration-based combined-cycle units. IEEE Trans. Power Syst. 2016, 31, 1350-1359. [CrossRef]

39. IRENA. Renewable Power Generation Costs in 2017; International Renewable Energy Agency: Abu Dhabi, United Arab Emirates, 2019.

40. Zhao, J.; Liu, D.C.; Yang, N.; Sun, W. Operation mode and benefits of nuclear power plant participating in peak load regulation of power system. Power Syst. Technol. 2012, 36, 250-255.

41. Hetzer, J.; Yu, D.C.; Bhattarai, K. An Economic Dispatch Model Incorporating Wind Power. IEEE Trans. Energy Convers. 2008, 23, 603-611. [CrossRef]

42. Wang, J.; Zhao, J.; Ye, X.; Liu, D.; Weng, Y.; Wang, L.; Wang, H. Safety constraints and optimal operation of large-scale nuclear power plant participating in peak load regulation of power system. IET Gener. Transm. Distrib. 2017, 11, 3332-3340. [CrossRef]

43. Jabr, R.; Pal, B.; Jabr, R. Intermittent wind generation in optimal power flow dispatching. IET Gener. Transm. Distrib. 2009, 3, 66-74. [CrossRef]

(C) 2019 by the authors. Licensee MDPI, Basel, Switzerland. This article is an open access article distributed under the terms and conditions of the Creative Commons Attribution (CC BY) license (http://creativecommons.org/licenses/by/4.0/). 